\title{
FREMDHERRSCHAFT UND DEKOLONISIERUNG IN RECHTLICHER SICHT
}

\author{
Von Albert Bleckmann
}

Die folgende Abhandlung versucht, aus der 1969 erschienenen Monographie des Verfassers über „Das französische Kolonialreich und die Gründung neuer Staaten. Die Rechtsentwicklung in Syrien/Libanon, Indochina und Schwarzafrika"1 eine vorläufige Bilanz für die allgemeine Staatslehre zu ziehen. Sie will zeigen, daß die traditionelle, auf einem bestimmten Verständnis des Souveränitätsbegriffs beruhende Staatslehre insbesondere in der ihr von G. Jellinek gegebenen klassischen Form, die das deutsche Staats- und Völkerrechtsdenken stark beeinflußt hat, zahlreichen Phänomenen der Fremdverwaltung, des Integrations- und Desintegrationsprozesses von Staaten nicht Rechnung tragen kann. Diese klassische Auffassung kann man als "Ergreifungstheorie“ bezeichnen. Die staatliche Rechtsordnung ruht nach dieser Theorie in sich selbst. Staatsgründungen, die Ausdehnung des Staatsgebiets, der Rechtsordnung, der Kompetenzen, die Unabhängigkeit schließlich sind nur in der Weise denkbar, daß der Staat entsprechende Akte autonom setzt. Eine historisch gesehen heteronome Staatsgründung, Verfassungs- oder Gesetzgebung muß entweder in eine autonome Staats-, Verfassungs- oder Gesetzgebung umgedeutet werden oder es fehlt dem neuen Gebilde die Souveränität und damit auch die Staatseigenschaft. Logisch konsequent sind ferner bestimmte Kontinuitäten auf der völker- oder staatsrechtlichen Ebene ausgeschlossen: eine Gebietszession muß als Rückzug des zedierenden Staates aus dem betreffenden Gebiet mit logisch nachfolgender Annexion dieses Gebiets durch den Zessionar, die Staatensukzession kann nur als Ubernahme eines Rechts oder einer Pflicht aufgrund des Willens des Nachfolgestaates verstanden werden. Die Unabhängigkeit kann niemals durch einen Akt des Gesamtstaats, sondern nur durch einen Akt des sich losreißenden Staates eintreten.

Völker- und staatliches Recht sind streng voneinander getrennt: Innerhalb des Gebiets eines Staates kann nur staatliches Recht, zwischen zwei Staaten kann nur Völkerrecht gelten; die Beziehungen zwischen zwei Gebieten sind also immer entweder dem Staats- oder dem Völkerrecht zuzuordnen. Bei einem mehrere Staaten umfassenden Integrationsprozeß gilt bis $\mathrm{zu}$ einem bestimmten Punkt das Völkerrecht; von diesem Punkt (Bundesstaat) an springt das ganze Beziehungsgebilde ins Staatsrecht über. Genau umgekehrt gilt beim Desorganisationsprozeß eines einheitlichen Staates bis zu diesem Punkt das Staatsrecht, von da an einheitlich Völkerrecht. Dadurch werden die vielfältigen Gemengelagen von Völker- und Staatsrecht vor und nach diesem Punkt kaschiert. Unbegreifbar bleibt so etwa die Tatsache, daß zahlreiche vor der Unabhängigkeit geschlossene Verträge zwischen dem Mutterland und den neuen Staaten oder zwischen diesen Staaten nach der Unabhängigkeit in ihrer Qualität unverändert weitergelten, daß die Verbindung der Rechtsordnung der neuen Staaten mit dem Mutterland auch nach der Unabhängigkeit nie ganz abreißt ${ }^{2}$, daß etwa in der französischen Ge-

\footnotetext{
1 Seitenangaben ohne nähere Bezeichnung beziehen sich auf diese Arbeit. Vgl. auch die Besprechung in VRU 1970, S. $111 \mathrm{f}$. Dazu vom gleichen Verfasser die Stichwörter "Afrikanische Zusammenschlüsse“ und "Französische Gemeinschaft" in den Ergänzungsbänden des Staatslexikons.

2 Vgl. etwa die Entwicklung in Schwarzafrika, S. $333 \mathrm{ff} ., 336 \mathrm{ff}$.
} 
meinschaft, im britischen Commonwealth nicht durch Mandat oder Delegation der Neustaaten, sondern nur durch den Fortbestand von Relikten des früheren umfassenden Staatsverbandes erklärbare gemeinsame Rechtsordnungen ${ }^{3}$ oder Kompetenzen des Mutterlands $s^{4}$ erhalten bleiben.

$\mathrm{Zu}$ all diesen Fragen will die im folgenden entwickelte Kontinuitätstheorie im Ansatz neue Lösungen vorschlagen. Der Verfasser ist sich dabei bewußt, daß diese Lösungen weitere Forschungen im Bereich der allgemeinen Staatslehre, des Völkerrechts und des vergleichenden Staatsrechts erfordern, und daß insbesondere auch das Kolonialrecht Großbritanniens, der Niederlande, Spaniens, Portugals und Deutschlands sowie das bei den deutschen, japanischen und alliierten Besetzungen entwickelte Recht in eine umfassendere Forschungsarbeit einbezogen werden müßte. Ich hoffe, die Ergebnisse einer solchen Forschung in absehbarer Zeit vorlegen zu können.

\section{Die koloniale Fremdherrschaft}

1) Die Kolonialherrschaft ist wie die militärische Besetzung ein Unterfall der Fremdherrschaft, die ihrerseits wiederum zumindest teilweise den auf Ungleichheit beruhenden Staatenverbindungen einzuordnen ist.

a) In der Literatur wird zwar die Einheit des kolonialen Phänomens, nicht aber dessen begriffliche Zuordnung richtig erkannt. Obwohl die Kolonialgebiete einen sehr unterschiedlichen Status (Kolonien, territoires d'outre-mer, départements d'outre-mer, innerstaatliche und völkerrechtliche Protektorate, Mandats- und Treuhandgebiete, Verwaltungszessionen, Kondominien usw.) besitzen, wurde namentlich im französischen Bereich die Einheitlichkeit des kolonialen Phänomens frühzeitig erkannt. Auf diesem Begriff der Kolonialherrschaft beruht die Einheit des französischen Imperiums und damit die Möglichkeit, das „droit d'outre-mer“ als eine mehr oder minder geschlossene Rechtsmaterie darzustellen ${ }^{5}$. Dieser Begriff ist aber auch die Klammer, welche in neuerer Zeit die Dekolonisierung als einheitlichen Prozeß begreifen läßt $t^{6}$, in dem bestimmte Rechtsfragen wie etwa die Staatensukzession einheitlich behandelt werden müssen ${ }^{7}$. Allerdings hat die Literatur über das Kolonialrecht und die Dekolonisierung den Begriff der Kolonialherrschaft und dessen Einordnung in ein umfassenderes Begriffssystem nur selten untersucht.

Solche theoretischen Ansätze zur Eingliederung der Kolonialherrschaft in ein umfassenderes Begriffssystem finden sich dagegen in den Lehren von den Staaten-

3 S. 445 für das Verhältnis Frankreichs zu den afrikanischen Staaten; S. 163 ff., $466 f f$. für das Verhältnis der Neustaaten zueinander.

$4 \mathrm{Vgl}$. etwa den Fortbestand der französischen Gerichtsbarkeit in Indochina (S. $167 \mathrm{ff}$.) und in Schwarzafrika (S. $443 \mathrm{ff}$.) während einer Ubergangszeit; noch treffender die Zuständigkeiten des Privy Council im Commonwealth.

5 Vgl. L. Rolland et P. Lampué, Précis de droit des pays d'outre-mer, 1952; F. Luchaire, Manuel de droit d'outre-mer, 1949 sowie: Droit d'outre-mer, 1959, und: Droit d'outre-mer et de la coopération, 1966; P. F. Gonidec, Droit d'outre-mer, 2 Bde., 1959/60.

6 Vgl. etwa E. Kordt, Gegenwärtige Fragen der Staatensukzession, Verhandlungen der 8. Tagung der Deutschen Gesellschaft für Völkerrecht in Würzburg vom 28. bis 30. April 1963; Berichte der deutschen Gesellschaft für Völkerrecht, Heft 5; H. U. Scupin (Herausgeber) Unvollendete Demokratien, Organisationsformen und Herrschaftsstrukturen in nichtkommunistischen Entwicklungsländern in Asien, Afrika und im Nahen Osten, 1965

7 Vgl. neben zahlreichen Aufsätzen insbesondere: The Effect of Independence on Treaties. A Handbook published under the Auspices of the International Law Association. Prepared by the Committee on State Succession to Treaties and other Governmental Obligations, 1965; ferner: K. Zemanek, in: Gegenwärtige Fragen der Staatensukzession, a. a. O. 
verbindungen und der militärischen Besetzung. So bezieht etwa Kunz unter Rückgriff auf ältere Autoren wie Jellinek, Laband und Rehm unter die „Staatenverbindungen auf der Grundlage staatsrechtlicher Ungleichheit" auch die Protektorate und Mandate ein ${ }^{8}$. Diese Definition erfaßt zwar nicht das gesamte Phänomen der Fremdherrschaft, ja noch nicht einmal das der Kolonialherrschaft, zeigt aber andererseits gewisse Analogien dieser Herrschaft mit anderen Staatenverbindungen, insbesondere den Bundesstaaten auf, soweit auf dem Kolonialgebiet ein einheimischer Staat existiert, der dem Herrscherstaat rechtlich unterworfen ist ${ }^{9}$.

Die Lehre von der militärischen Besetzung versucht, von der kriegerischen Besetzung ("occupation belligérente“) ausgehend $\mathrm{zu}$ umfassenderen Begriffen vorzustoßen, die ebenfalls gewisse Formen der Kolonialherrschaft einschließen. So unterschied schon Robin zwischen der "occupation militaire en cas de guerre" und der "occupation militaire en dehors du cas de guerre", die ihrerseits wieder in die "occupation de correction ou de police“ und die "occupation conventionnelle" unterteilt wurde ${ }^{10}$. Bei der "occupation conventionnelle“ zählte Robin die Besetzung aufgrund von „traités de paix, d'alliance, de protectorat" auf. Diese Lehre wurde bei der Besetzung Deutschlands nach dem zweiten Weltkrieg weiter ausgebaut. So unterteilte Sauser-Hall die "occupation militaire“ in die "occupation de guerre, occupation pacifique, occupation mixte, occupation tutélaire", und teilte die "occupation pacifique“ wiederum in drei Gruppen: „à titre de garantie, administrative, coercitive" auf. Die "occupation militaire pacifique à titre administratif“ umfaßt dabei die sogenannten Verwaltungszessionen und Pachtverträge ${ }^{11}$. An Sauser-Hall schlossen sich mit gewissen Abweichungen und Erweiterungen Bindschedler ${ }^{12}$ und Uhler ${ }^{13}$ an.

Die Lehre von der militärischen Besetzung hat damit richtig erkannt, daß zwischen der militärischen und der kolonialen Fremdherrschaft Gemeinsamkeiten bestehen, die eine Unterscheidung manchmal sehr schwierig machen ${ }^{14}$ und einen kontinuierlichen Übergang von der einen zur anderen Herrschaftsform gestatten ${ }^{15}$. Auch das gemeinsame Kriterium, die Herrschaft über ein fremdes Gebiet, klingt im Terminus "Besetzung“ schon deutlich an. Dennoch scheint mir der Begriff der Fremdherrschaft ${ }^{16}$ den Vorzug zu verdienen. Einmal kann nämlich die „Besetzung“ nicht die in den Staatsverband des Herrscherstaates eingegliederten Kolonialgebiete erfassen, zum anderen stellt dieser Terminus zu stark einen zwar stets vorhandenen, aber zumindest bei einigen ihrer Formen doch nur untergeordneten Faktor der Fremdherrschaft: die Besetzung durch die Armee des Herrscherstaates, heraus und vernachlässigt damit das wesentliche gemeinsame Kriterium, eben die

8 J. L. Kunz, Die Staatenverbindungen, Handbuch des Völkerrechts, 1929 IV. Diese Einteilung wird von den modernen Lehrbüchern übernommen, vgl. etwa A. Verdross, Völkerrecht, 5. Aufl. 1964, S. 356 . D. W. Gunst, Der Begriff der Souveränität im modernen Völkerrecht, 1953, folgt einer etwas unterschiedlichen Gruppierung.

9 S. u. II.

10 R. Robin, Des occupations militaires en dehors des occupations de guerre, 1913.

11 G. Sauser-Hall, L'occupation de l'Allemagne par les Puissances Alliées, Schweizerisches Jahrbuch für Internationales Recht, Bd. III, 1946, S. 9.

12 R. L. Bindschedler, Die völkerrechtliche Stellung Deutschlands, Schweizerisches Jahrbuch für Internationales Recht, Bd. IV, 1949, S. 37.

$13 \mathrm{O}$. M. Uhler, Der völkerrechtliche Schutz der Bevölkerung eines besetzten Gebiets gegen Maßnahmen der Okkupationsmacht, 1950, S. $33 \mathrm{ff}$.

14 Diese Schwierigkeiten zeigten sich insbesondere bei der Besetzung Deutschlands, vgl. etwa v. Meister, Stimmen des Auslands zur Rechtslage Deutschlands, ZaöRV Bd. 13, 1951, S. 173 ff.

$15 \mathrm{Hier}$ sei an den Übergang der französischen Besetzung in die Mandats- und Treuhandverwaltung in Syrien-Libanon (S. $17 \mathrm{f}$.) und in Togo-Kamerun (S. $242 \mathrm{ff}$.) und der französischen Protektorats- und Kolonialverwaltung in die japanische Besatzungsverwaltung in Indochina (S. $113 \mathrm{ff}$.) erinnert.

16 Soweit ersichtlich, wird dieser Terminus - allerdings in einem etwas anderen Sinne - nur von E. Kaufmann, Deutschlands Rechtslage unter der Besatzung, 1948, S. $27 \mathrm{f}$. und von Schmoller-Maier-Tobler, Handbuch des Besatzungsrechts, Bd. I, 1957, S. 5 benutzt. 
- bei einer gewissen Dauer regelmäßig von einer Zivilverwaltung getragene „Herrschaft" über das „fremde“ Gebiet.

b) Fremdherrschaft ist die Herrschaft eines Staates über ein fremdes Gebiet. Dabei kann sowohl die „Herrschaft" wie die "Fremdheit" im politischen und im rechtlichen Sinne definiert werden. Im rechtlichen Sinne ist ein Gebiet fremd, wenn es nicht zum Territorium des herrschenden Staates gehört, im soziologischen oder politischen Sinne auch dann, wenn es zwar im Verband des Herrscherstaates, seine Bevölkerung aber außerhalb der staatstragenden Nation steht. Von Herrschaft im rechtlichen Sinne sprechen wir, wenn diese sich in rechtlichen Strukturen verfestigt hat; die politische Herrschaft umfaßt auch den Einfluß der Regierung oder vor allem der regierenden (Einheits-) Partei eines Staates auf die Regierung oder die regierende (Einheits-) Partei eines anderen Staates. Innerhalb dieser Kategorien werden nach dem Rechtsgrund und den Herrschaftsstrukturen verschiedene Formen unterschieden. So kommt man $\mathrm{zu}$ folgendem, allerdings nur die moderneren Herrschaftsverhältnisse berücksichtigenden Schema:

politische Herrschaft eines Staates über rechtlich fremde Gebiete: Satellitenverhältnisse und Einflußsphären;

rechtliche Herrschaft eines Staates über rechtlich fremde Gebiete: Protektorate, Mandate, Treuhandgebiete, Verwaltungszessionen einerseits, militärische Besetzung andererseits;

rechtliche Herrschaft eines Staates über nur politisch fremde Gebiete: Kolonien und überwiegend von nationalen Minderheiten bewohnte Gebiete.

c) Sowohl die militärische als auch die koloniale Fremdherrschaft ist also Herrschaft im rechtlichen Sinne. Im Gegensatz zur militärischen Fremdherrschaft, die nur auf rechtlich fremdem Gebiet ausgeübt werden kann, umfaßt die Kolonialherrschaft darüber hinaus auch im Staatsverband des Mutterlands stehende, also nur politisch fremde, „abhängige“ Gebiete. Dabei können die Herrschaftsbeziehungen auf den verschiedensten Rechtsgrundlagen beruhen. Trotzdem erscheint eine umgreifende Definition möglich:

Kolonialherrschaft ist die dauernde rechtliche Beherrschung von inner- oder außerhalb des Staatsverbands des Herrscherstaates stehenden vom Mutterland räumlich getrennten Gebieten, deren Bevölkerung aus ethnischen und kulturellen Gründen außerhalb der Nation des Mutterlandes steht ${ }^{17}$. Außerhalb dieser Nation steht eine Bevölkerung vor allem dann, wenn sie sich ihr fremd fühlt. Dieses Gefühl kann vor allem durch eine ungleiche Behandlung des Herrscherstaats ausgelöst werden. Eine solche Diskriminierung ist aber nicht unbedingt erforderlich ${ }^{18}$.

So ist es bekanntlich Frankreich nicht gelungen, durch die rechtliche Assimilation der Überseegebiete und ihrer Bewohner die Dekolonisierung aller Fremdgebiete aufzuhalten. Dasselbe könnte eines Tages für die in das Mutterland rechtlich voll integrierten portugiesischen Überseeprovinzen gelten, obwohl natürlich die volle Integration auch bewirken kann, daß die Überseebevölkerung sich eines Tages als Teil der herrschenden Nation fühlt.

\footnotetext{
17 Die Definition von M. Merle, La décolonisation, Annales de la Faculté de Droit de Liège, 11. Jg. 1966, No. 1 und 2, S. $38 \mathrm{ff} ., 34$ : „Or, la colonisation se définit, quelles que soient ses modalités particulières d'application, par un statut "de dépendance juridique qui permet à une puissance extérieure de gérer ou d'application, par un statut de dépendance juridique qui permet à une puissance extérieure de gérer ou
de contrôlier la gestion d'un autre pays" ist einerseits zu weit, weil sie auch die militärische Fremdherrschaft erfaßt, andererseits zu eng, weil sie sich im Kern nur auf rechtlich fremde Gebiete bezieht.

18 So aber J. L. Quermonne, auf dessen Definition unter II 1a) näher eingegangen wird.
} 
2. Versuchen wir nunmehr, den Begriff der Herrschaft näher zu definieren. Nach Heller ${ }^{19}$ heißt herrschen: „bestimmt befehlen, bindend entscheiden.“ Genauer definiert Laband ${ }^{20}$ : „Herrschen ist das Recht, freien Personen (und Vereinigungen von solchen) Handlungen und Leistungen zu befehlen und sie zur Befolgung derselben zu zwingen...; das Wesen des Hoheitsrechts... besteht in der rechtlich anerkannten Gewalt über ihn, kraft dem derselbe gezwungen wird, dem an ihn ergangenen Befehl zu gehorchen." Herrschaft ist also Ausübung von Hoheitsgewalt über Personen und Personenvereinigungen, insbesondere auch Länder und Staaten. In beiden Formen tritt auch die Fremdherrschaft auf ${ }^{21}$.

Fremdherrschaft bedeutet aber darüber hinaus infolge der Überordnung des Herrscherstaates auch Innehabung der höchsten politischen oder sogar rechtlichen Gewalt auf dem politisch oder rechtlich fremden Gebiet. Der Herrscherstaat besitzt also in einem noch näher zu definierenden Sinne auch die Souveränität über dieses Territorium. Das ist ohne Rücksicht auf die Definition der Souveränität im Verhältnis zu den nur politisch fremden Gebiet stets der Fall. In dem Verhältnis zu dem rechtlich fremden Gebiet hängt die Souveränität des Herrschers davon ab, ob die Definition dieses Begriffs mehr auf die faktisch-politischen oder auf die rechtlichen Befugnisse abzielt und wieweit insbesondere die rechtlichen Befugnisse im Einzelfall gehen.

Bei der Definition der Souveränität ist nun bei fast allen Autoren hinsichtlich dieser Befugnisse eine gewisse Unbestimmtheit festzustellen. Wendet man die verschiedenen Definitionen der sogenannten „inneren“ Souveränität auf das Verhältnis des Herrscherstaates zum beherrschten 'Gebiet an, kommt man insbesondere bei der Kolonialherrschaft fast immer zu dem Ergebnis, der Herrscherstaat habe die Souveränität auch über die rechtlich fremden Gebiete. Denn auch im Verhältnis etwa zum protegierten Staat besitzt der Herrscherstaat zumindest polit is ch die höchste Gewalt (suprema potestas)22, die keiner anderen Gewalt unterworfen ist und der alle anderen Gewalten entfließen; die Kompetenzhoheit ${ }^{23}$ und die Macht zur Bestimmung des Ausnahmezustands ${ }^{24}$; die Macht zur Positivierung der obersten, die Gemeinschaft determinierenden Rechtsgrundsätze ${ }^{25}$; die Möglichkeit, jede die Einheit des gebietsgesellschaftlichen Zusammenwirkens betreffende Frage gegebenenfalls sogar gegen das positive Recht entscheiden zu können und diese Entscheidung jedermann aufzuerlegen ${ }^{26}$; die Eigenschaft einer souveränen Gebietsentscheidungs- und Wirkungseinheit, kraft welcher sie um des Rechts willen sich auch gegen das Recht absolut behauptet ${ }^{27}$. Denn noch über das Wirken der Besatzungsmächte etwa in Deutschland weit hinausgehend bestimmte Frankreich sogar in den Protektoratsstaaten Nordafrikas und Indochinas entweder unmittelbar oder über seine Kontrolle - mittelbar durch die Staaten - nicht nur grundsätzliche Fragen des Zusammenwirkens und der einheimischen Verfassungen, sondern alle Sachfragen bis ins letzte Detail.

19 H. Heller, Die Souveränität, 1927, S. 38.

20 P. Laband, Das Staatsrecht des Deutschen Reiches, Bd. I, 1911, S. 68 f

21 Für das besetzte Deutschland vgl. die Rechtspnechungsberichte von H. J. Hahn, ZöRV Bd. 14, 1951: 52, S. $278 \mathrm{ff}$., $292 \mathrm{ff}$., von F. Münch ZaöRV Bd. 21, 1961, S. $511 \mathrm{ff}$., 537 sowie: G. Jaenicke, Der Abbau der Kontrollratsgesetzgebung, 1952, S. 12; für das französische Imperium s. u.

22 Vgl. die bei Rosenbaum, Der Souveränitätsbegriff, 1932, S. 27, 41 wiedergegebenen Definitionen von Borel, de Louter und v. Liszt.

23 A. Haenel, Studien zum deutschen Staatsrecht, Bd. I, 1873, S. 149.

24 C. Schmitt.

$25 \mathrm{H}$. Heller, a. a. O., S. 52.

26 H. Heller, a. a. O., S. 52

27 H. Heller, a. a. O., S. 160 
Kommt es nur auf den hinter der Rechtsordnung stehenden Willen ${ }^{28}$ und damit auf die machtpolitische Lage an, besitzt der Herrscherstaat über die Fremdherrschaft regelmäßig auch die Souveränität über das fremde Gebiet. Eine so weitgehende Folgerung hat, soweit ersichtlich, keiner der genannten Autoren aus seinen Definitionen gezogen. Wie dies schon aus manchen Formulierungen hervorgeht, muß die hierin umschriebene Herrscherstellung vielmehr auf das Recht gestützt sein. Nach Haenel ${ }^{29}$ und Heller ${ }^{30}$ scheinen dabei auch Kontrollrechte des Herrscherstaates jedenfalls dann nicht auszureichen, wenn sie dem beherrschten Staat nur Pflichten auferlegen und seine inneren Befugnisse auf dem betreffenden Gebiet belassen. Erst wenn der Herrscherstaat innere Hoheitsbefugnisse unmittelbar ausübt, soll die Souveränität des beherrschten Staates verlorengehen. $\mathrm{Ob}$ der Herrscherstaat damit die Souveränität erwirbt, wird von Heller nur indirekt beantwortet, indem er darauf hinweist, hier handle es sich um eine verschleierte Methode der Kolonialbildung.

Diese kurze Darstellung zeigt, wie unbefriedigend der Souveränitätsbegriff auch unter dem Gesichtspunkt der Fremdherrschaft ist. In der Tat sagt er in dieser Allgemeinheit weder zur rechtlichen noch zur politischen Lage etwas aus. Dennoch kann er wertvolle Erkenntnisse vermitteln, wenn zwischen verschiedenen Begriffen unterschieden wird, welche die verschiedenen, manchmal sich auch widersprechenden Elemente der Souveränität nach jeweils anderen Gesichtspunkten ordnen. So legt es die bisherige Untersuchung nahe, zwischen der politischen und der rechtlichen Souveränität zu unterscheiden. Unter der politischen Souveränität ist dann die faktisch höchste politische Gewalt, der politische Wille zu verstehen, welcher eine keiner anderen Gewalt unterworfene Gebietsentscheidungsund Wirkungseinheit begründet. In diesem Sinne besaß Frankreich die Souveränität über alle Kolonialgebiete ohne Rücksicht auf deren rechtlichen Status, bildete das französische Imperium eine von Frankreich gelenkte politische Wirkungseinheit. In der Tat war Franlsreich im Sinne Haenels ${ }^{31}$ in Betracht seiner Strukturen höchster, weil umfassendster korporativer Verband ${ }^{32}$, in Betracht seiner Leistung höchster, weil alle gesellschaftlich zu verwirklichenden $Z$ wecke zu einem Gesamtplan geordneten Zusammenwirkens zusammenfassender Gemeinzweck, in Betracht seiner Funktion höchster, weil alle Willensmächte und Herrschaften von der Seite jener Gesamtordnung ergreifende und sich unterordnende Herrschaft.

Von rechtlicher Souveränität ${ }^{33}$ sprechen wir dagegen in einer ersten Annäherung, wenn diese politische Herrschaft in Rechtssätzen Niederschlag gefunden hat. Diese Formel trifft zwar den Normalfall des unabhängigen Staates, erscheint aber bei der Einbeziehung der Fremdherrschaft als zu eng, weil, wie die obigen Zitate zeigen, auch der Staat im formalrechtlichen Sinne nach innen souverän ist, der vollkommen dem Willen eines anderen Staates unterworfen ist, sofern er nur formell alle staatlichen Hoheitsbefugnisse zumindest nach innen behält. Das bedeutet auf der anderen Seite, daß es für die Begründung der rechtlichen Souveränität des Herrscherstaates über das beherrschte Gebiet nicht ausreicht, wenn diese

28 W. von Simson, Die Souveränität im rechtlichen Verständnis der Gegenwart, 1965, S. 31: „Souveränität in abstracto ist das faktisch einer jeden Rechtsordnung zugrundeliegende und diese Rechtsordnung in sich aufnehmende, von der Rechtsordnung selbst aber nicht erfaßbare Willensmoment."

29 A. Haenel, Deutsches Staatsrecht, Bd. 1, 1892, S. 118.

$30 \mathrm{H}$. Heller, a. a. O., S. 146.

32 Zur politischen Mediatisierung der indochinesischen Protektorate s. S. 134

33 Wie aus dem Folgenden ersichtlich, lehnt sich dieser Begriff entfernt an die "Rechtssouveränität ${ }^{\star}$ Krabbes und Kelsens an. Auf eine nähere Abgrenzung von diesem Begriff muß hier allerdings verzichtet werden. 
politischen Leitungsbefugnisse rechtlich verankert sind. Für die rechtliche Souveränität kommt es also entscheidend darauf an, wer formell Träger der staatlichen, das heißt aber nicht weiter ableitbaren Hoheitsgewalten über ein bestimmtes Gebiet ist ${ }^{34}$. Aber auch diese Definition bereitet bei der Fremdherrschaft wie bei den Staatenverbindungen noch Schwierigkeiten. So gibt es die C-Mandate, die Treuhandgebiete ${ }^{35}$ und sogar gewisse Protektoratsländer ${ }^{36}$, in denen der Herrscherstaat eigene Hoheitsgewalt ausübt, ohne daß man in einem engeren Sinne von rechtlicher Souveränität sprechen kann: rechtliche Souveränität liegt in diesem Sinne also nur dann vor, wenn ein Staat Träger der Hoheitsrechte über rechtlich eigenes Gebiet ist (Gebietssouveränität) ${ }^{37}$. Um die Trägerschaft eigener Hoheitsrechte über Personen und Staaten auf rechtlich fremdem Gebiet zu kennzeichnen, kann man von einer Funktions- oder Kompetenzsouveränität sprechen. Der Gebiets- oder Vollannexion entspricht dann die Kompetenzannexion, der Gebietszession die Kompetenzzession. Auf diese Weise wird ein Dilemma vermieden, das auftritt, wenn man nur die Vollannexion kennt: daß man nämlich entweder die Befugnisse des Herrscherstaates übersehen oder von einer Vollannexion ausgehen muß.

Nicht bei jeder Ausübung von Hoheitsgewalt auf fremdem Gebiet ${ }^{38}$ kann man allerdings auch schon von „Kompetenzsouveränität“ sprechen. Dabei ist zu beachten, daß es für die folgende Einteilung nicht auf die politische Souveränität, sondern auf die formelle Rechtslage ankommt, die trotz der einheitlichen politischen Souveränität des die Hoheitsgewalt ausübenden Staates höchst verschieden gestaltet sein kann. Kompetenzsouveränität bedeutet zunächst Ausübung der Hoheitsgewalt im eigenen Namen. Damit werden die Fälle ausgeschieden, wo ein Staat im fremden Namen Hoheitsgewalt auf dem fremden Gebiet ausübt ${ }^{39}$. Kompetenzsouveränität ist aber weiter Ausübung von Hoheitsgewalt aus eigenem, das heißt aber ursprünglichem, nicht abgeleitetem Recht. Damit werden nur Hoheitsbefugnisse erfaßt, die der Substanz und nicht nur der Ausübung nach auf den Herrscherstaat übergegangen sind ${ }^{40}$. Dieses Begriffspaar und insbesondere der Gedanke der Kompetenzübertragung ist zunächst einmal überhaupt nur auf Hoheitsgewalten anzuwenden, die ihrem Wesen nach in den Bereich des beherrschten Staates fallen. Ausgeschieden werden damit vor allem die Hoheitsgewalten, die ihrem Wesen nach in den Bereich des Herrscherstaates fallen. Hierdurch werden alle Kompetenzen erfaßt, die wie etwa die Konsulargewalt auch im Verhältnis zwischen unabhängigen Staaten einem fremden Staat auf dem eigenen Hoheitsgebiet eingeräumt $\mathrm{zu}$ werden pflegen. Nur soweit die Hoheitsrechte wie etwa die

34 P. Laband a. a. O.: „Herrschermacht zu eigenem Recht ${ }^{\alpha}$; ähnlich G. Jellinek (Allgemeine Staatslehre, 5. Neudruck der 3. Auflage, 1928, S. 430, 489), der zwischen der "ursprünglichen ${ }^{*}$ und der "abgeleiteten ${ }^{*}$ Gewalt unterscheidet. Vgl. hierzu die Kritik von H. Kelsen (Das Problem der Souveränität und die Theorie des Völkerrechts, 1920, S. 56 ff., 66 ff.).

35 S. 243.

$36 \mathrm{Vgl}$. Indochina, S. $91 \mathrm{ff} ., 106 \mathrm{ff}$.

37 A. Verdross (Völkerrecht, 5. Aufl. 1964, S. 266) unterscheidet zwischen der „dem Eigentum entsprechenden* territorialen Souveränität und der "dem Besitz entsprechenden “ Gebietshoheit. Die territoriale Souveränität bezeichnet hier also nur die rechtliche Zugehörigkeit des betreffenden Gebiets zu einem bestimmten Staat. Diese Lehre wird hier insoweit abgewandelt, als der Akzent vom „Eigentum an dem Gebiet ${ }^{\alpha}$ auf das „Eigentum an den Kompetenzen“ verlagert und so eine Verbindung dieser Lehre mit der Theorie der Kompetenzträgerschaft geschaffen wird. Wie die Anführungszeichen zeigen, ist dabei der Begriff des Eigentums nicht technisch, sondern in einem übertragenen Sinne gemeint. Eine solche Rückkehr zu "privatrechtlichen Analogien* entspricht ebenso wie die verstärkte Unterstreichung der Kompetenzen einer moderneren Ausrichtung der Völker- und Staatsrechtstheorie, die wegen der Einseitigkeit der aus dem Wesen des Staates entwickelten Theorien notwendig wird (s. u.).

38 Eine Ubersicht findet sich bei K. W. Geck, Hoheitsakte auf fremdem Staatsgebiet, Wörterbuch des Völkerrechts, Bd. 1, 1960, S. 765.

39 Zum Typ des in den beherrschten Staat integrierten Fremverwaltung s. u. I 4 b.

$40 \mathrm{Zu}$ dieser Unterscheidung vgl. K. H. Klein, Die UUbertragung von Hoheitsrechten, 1952, S. 29. 
Befugnisse über die eigenen Staatsangehörigen wesensmäßig in den Bereich des beherrschten Staates fallen, ist also zwischen der Innehabung zur Ausübung und der Substanz nach zu unterscheiden. Bei der Übertragung zur Ausübung bleibt die betreffende Befugnis noch so stark mit dem beherrschten Staat verbunden, daß dieser hinsichtlich seiner Einheit zumindest dem Grunde nach noch völlig intakt bleibt. Dagegen wird bei der Substanzübertragung die betreffende Befugnis endgültig und vollkommen aus dem Kreis der staatlichen Befugnisse herausgebrochen. Es kommt also darauf an, inwieweit die betreffende Gewalt noch in das alte oder schon in das neue staatliche System integriert ist. Anzeichen hierfür sind etwa der Grad der Beteiligung der Zentralinstanzen des Herrscherstaates, der provisorische oder endgültige Charakter der Übertragung, der Umfang der übertragenen Befugnisse und der Grad, in welchem die Ausübung dieser Befugnisse auch weiterhin vom Willen des beherrschten Staates abhängt: wie wir im folgenden sehen werden, erreichte die "Französisierung" der von der französischen Republik ausgeübten Befugnisse in Indochina ihren höchsten Stand, ohne daß man schon von einer Gebietsannexion sprechen könnte.

Diese Konstruktionen erklären insbesondere auch den Fall, daß die Kompetenzen auf demselben Gebiet zwischen zwei Staaten aufgeteilt sind, wie wir es beim Bundesstaat und besonders häufig auch bei der Fremdherrschaft finden. Laband hat dieses Problem aus dem Blickwinkel des Bundesstaates untersucht und zur Lösung die Kompetenzträgerschaft herangezogen; statt von „Kompetenzsouveränität“ spricht er hier allerdings vom „Imperium" ${ }^{41}$. Das ist sicher richtig, wenn der beherrschte Staat dem Herrscherstaat auch rechtlich unter- oder sogar eingeordnet ist (Bundesstaat und bundesstaatsähnliche Strukturen der Fremdherrschaft). Trotzdem ist die Bezeichnung „Kompetenzsouveränität“ jedenfalls dann vorzuziehen, wenn der souveräne Herrscherstaat alle Kompetenzen über ein rechtlich fremdes Gebiet in eigenem Namen und aus eigenem Recht ausübt oder wenn zwei formell souveräne und deshalb rechtlich nebengeordnete Staaten sich in die Kompetenzen teilen, ganz gleich ob es sich hierbei um zwei Herrscherstaaten oder um den herrschenden und den beherrschten Staat handelt. Die von der Lehre befürchtete Kampfsituation ${ }^{42}$, zu deren Vermeidung das Dogma der einzigen und ausschließlichen Gebietssouveränität begründet wurde ${ }^{43}$, kann hier nur im zweiten Fall entstehen, weil im ersten Fall der Herrscherstaat alle Kompetenzen ausübt und damit eine der Gebietssouveränität ähnliche Rechtslage entsteht, während im letzten Falle die doppelte rechtliche Souveränität durch die einheitliche politische Souveränität des Herrscherstaates aufgefangen wird. Auch im Fall der Teilung der Hoheitsgewalten zwischen zwei Herrscherstaaten braucht, wie das Beispiel der neuen Hebriden zeigt, eine solche Kampfsituation nicht notwendig zu entstehen. Uberdies erscheint es fraglich, ob das genannte Dogma angesichts des wachsenden Pluralismus in den westlichen Demokratien noch vertreten werden kann, wo die Einheit nicht mehr durch eine Befehlshierarchie, sondern durch Verhandlungen gleichgeordneter Partner erzielt werden muß.

41 Zur Souveränitäts- und Herrschaftstheorie Labands vgl. eingehend S. Rosenbaum, a. a. O., S. 73.

$42 \mathrm{Vgl}$. etwa H. Heller, a. a. O., S. 110

43 Anders aus seiner Lehre heraus natürlich H. Kelsen, a. a. O., S. 73 ff., der dieses Dogma auf die notwendige ${ }_{\text {SSystemeinheit }}{ }^{\star}$ zurüdkführt. 
3. Das Phänomen der Fremdherrschaft führt zu einer weiteren Korrektur überkommener Lehren. Wir sind es gewohnt, grundsätzlich nur im Bereich der nach außen abgeschlossenen hierarchischen Wirkungseinheit des Staates innerstaatliches Recht, im Bereich zwischen zwei solchen souveränen Wirkungseinheiten aber Völkerrecht anzuwenden und dabei diese Wirkungseinheiten nach der Gebietssouveränität $\mathrm{zu}$ begrenzen. Bei starker Vereinfachung ist nach dieser Formel zwischen zwei derselben Gebietssouveränität unterworfenen Gebieten Staatsrecht, zwischen zwei verschiedenen Gebietssouveränitäten unterworfenen Territorien Völkerrecht anzuwenden.

Die Fremdherrschaft und insbesondere das Auftreten der Kompetenzsouveränität zeigen nun sehr deutlich, daß dieses Schema ungenau ist, daß sich auf den völkerrechtlichen Beziehungen zwischen dem Herrscherstaat und dem rechtlich fremden beherrschten Gebiet staatsrechtliche Beziehungen aufbauen können ${ }^{44}$. In terminologischer Anlehnung an die Trennung von Grund- und Betriebsverhältnis im deutschen Verwaltungsrecht ${ }^{45}$ unterscheiden wir deshalb das Grundverhältnis von dem Organisationsverhältnis zwischen den beiden Gebieten ${ }^{46}$. Diese Unterscheidung soll helfen, einen im Völker- und im Staatsrecht recht häufigen Widerspruch im Status von Gebieten aufzuheben, nach dem ein und dasselbe Territorium hinsichtlich gewisser Beziehungen außerhalb, in anderen Beziehungen aber innerhalb eines bestimmten Staatsverbandes steht, die Beziehungen zwischen diesem Gebiet und dem Staatsverband also teils innerstaatlich, teils völkerrechtlich geregelt sind.

Dieser scheinbare Widerspruch tritt gerade bei der Fremdherrschaft sehr häufig auf. Rechtliche Herrschaft eines Staates über ein rechtlich fremdes Gebiet bedeutet doch nichts anderes, als daß dieses Gebiet im "Grundverhältnis“ außerhalb des Staatsverbandes steht, daß aber zwischen der unmittelbare Hoheitsgewalt ausübenden Fremdverwaltung und dem betreffenden Gebiet, das heißt seiner Bevölkerung oder dem beherrschten Staat, innerstaatliche Subordinationsbeziehungen bestehen; ist die Fremdverwaltung in den Herrscherstaat integriert ${ }^{47}$, wird das beherrschte Gebiet im "Organisationsverhältnis“ also in den Staatsverband des Herrscherstaats einbezogen (Kompetenzannexion).

Beispiele für dieses Phänomen sind die Verwaltungszessionen, die koloniale Treuhandschaft, die De-facto-Zessionen, rechtswidrige Zessionen und Annexionen sowie provisorische Eingliederungen als Vorläufer der Vollannexion. Alle diese Gebiete stehen im Sinne des Grundverhältnisses außerhalb des Staatsverbandes des Herrscherstaates, weil dieser über sie nicht die territoriale Souveränität besitzt; trotzdem werden sie meist so behandelt, "als ob“ sie im Staatsverband des Herrscherstaates stünden, sind sie also organisatorisch in diesen Verband einbezogen, unterstehen sie der gemeinsamen innerstaatlichen Rechtsordnung: das Organisationsverhältnis ist also im Gegensatz zum Grundverhältnis eindeutig innerstaatlich ausgerichtet.

Umgekehrt können sich auch in einem dem Grundverhältnis nach einheitlichen Staatsverband organisatorisch mehrere lokale oder nach Interessen oder Funktionen abgegrenzte Herrschaftszentren bilden, zwischen denen koordinationsrechtliche

\footnotetext{
44 Obwohl sich das moderne Völkerrecht bei der Einverleibung strukturwidriger Elemente in neuerer Zeit als äußerst flexibel erwiesen hat, kann man bei der Fremdverwaltung (Kolonial- und Besatzungsverwaltung!) schon angesichts des Umfangs der vom Herrscherstaat ausgeübten Befugnisse nicht mehr von

45 Vgl. C. H. Ule, Das besondere Gewaltverhältnis, 1957, in: VeröffVDStRL Heft 15.

46 Auch Verdroß hat, wie gezeigt, die Notwendigkeit einer solchen Unterscheidung gesehen. Doch dürfte die Trennung zwischen territorialer Souveränität und Gebietshoheit zu eng sein, um alle Fälle zu erfassen. $47 \mathrm{Vgl}$. hierzu unten $4 \mathrm{a}$.
} 
Rechtsbeziehungen völkerrechtsähnlicher oder sogar völkerrechtlicher Art entstehen. Die Desorganisation des Staatsverbandes beginnt hier also im Organisationsverhältnis und wirkt nur von einem bestimmten Punkt an auf das Grundverhältnis zurück. Diese Konstruktion ist für den Prozeß der Erlangung der Unabhängigkeit, aber auch für Sezessionen von Bedeutung. Möglicherweise kann diese Unterscheidung aber auch den umgekehrten Fall, die allmähliche Integration mehrerer souveräner Staaten in eine supranationale Gemeinschaft als Vorläufer eines gemeinsamen Staatsverbandes erklären helfen: Hier bleibt das Grundverhältnis im Völkerrecht verankert, während sich im Organisationsverhältnis schon innerstaatliche Elemente zeigen. Soweit die interessierten Parteien über die Zugehörigkeit eines bestimmten Gebiets zu dem einen oder anderen Staat sich nicht einigen können, verzichten sie schließlich häufig auf die Klärung dieses Grundverhältnisses und regeln nur das Organisationsverhältnis.

Die Unterscheidung zwischen dem Grund- und dem Organisationsverhältnis trennt das Organisationsverhältnis vom rechtlichen Souveränitätsbegriff (Abstraktionsprinzip) und ermöglicht damit eine über eine Schwarzweiß-Klassifizierung hinausgehende, der konkreten Rechtslage entsprechende Qualifizierung: Das Verhältnis zwischen zwei Staaten oder einem Staat und einem Gebiet braucht nicht mehr notwendig entweder völkerrechtlich oder innerstaatlich, sondern kann je nach den konkreten Beziehungen beides sein. Die mit der Integration oder Desintegration verbundene Statusumwandlung braucht also nicht mehr als ein Sprung vom Völker- ins Staatsrecht oder vom Staats- ins Völkerrecht, sondern kann auch als eine allmähliche Umwandlung gedacht werden, in der zunächst im Organisationsverhältnis das Subordinations- allmählich vom Koordinationsrecht oder das Koordinations- allmählich vom Subordinationsrecht verdrängt wird, bis an einem bestimmten Punkt auch das Grundverhältnis seine Natur ändert. Es handelt sich hier um eine dem Entwicklungsprozeß angemessene, auch der Geschichtsschreibung, der Wirtschaftswissenschaft und der Soziologie bekannte Anschauungsweise, nach der beim Auftreten eines neuen Idealtyps die diesem entsprechenden Strukturen nur allmählich die dem alten Typ zuzuordnenden Strukturen verdrängen, in der Übergangsperiode also beide Strukturprinzipien nebeneinander stehen.

Grund- und Organisationsverhältnis sind als zwei sich überlagernde Rechtsschichten zu begreifen, die sich gegenseitig beeinflussen (Interdependenz). Bei der Lösung einer konkreten Rechtsfrage ist dabei zu fragen, welcher Rechtsschicht sie einzuordnen ist; bei gewissen Problemen sind beide Rechtsschichten, ihr gegenseitiges Verhältnis und der Charakter des Entwicklungsprozesses zu berücksichtigen. In der Regel wird das Organisationsverhältnis vom Grundverhältnis getragen: Das Grundverhältnis begründet hier das Organisationsverhältnis und wirkt auf dessen Strukturen ein. So wird das Organisationsverhältnis der Protektorate, Mandate und Treuhandschaften durch im Völkerrecht verankerte Verträge begründet, beruht die Herrschaft über die Kolonien auf der territorialen Souveränität über diese Gebiete. In der Regel wirkt sich dieses Grundverhältnis ferner auf die Strukturen des Organisationsverhältnisses aus: Auf derselben Souveränität unterworfenen Gebieten besteht ein einziger Staat, auf zwei verschiedenen Gebietssouveränitäten unterworfenen Territorien bestehen zwei Staaten, die unter sich in Völkerrechtsbeziehungen treten. 
Wie gerade die obigen Beispiele zeigen; kann sich das Organisationsverhältnis aber auch den vom Grundverhältnis aufgezeigten Strukturen entziehen und eine neue Richtung einschlagen ${ }^{43}$. Diese neue Entwicklung kann auf dem Willen der nach dem Grundverhältnis zuständigen Kompetenzträger beruhen oder sich auch unabhängig von diesem Willen vollziehen. Die neuen Kompetenzträger können dabei nur bestimmte oder alle Hoheitsgewalten ausüben. Auch im letzten Fall bleibt das alte Grundverhältnis bestehen. Es kann aber der Fall eintreten, daß im Organisationsverhältnis so gehandelt wird, als ob es auf einem neuen Grundverhältnis beruhe.

Schlägt das Organisationsverhältnis eine vom Grundverhältnis verschiedene Entwicklungsrichtung ein, stellt sich die Frage, wie das neue Organisationsverhältnis auf das Grundverhältnis zurückwirkt. Entwickelt sich auf einem völkerrechtlichen Grundverhältnis ein staatsrechtliches Organisationsverhältnis, schlägt das Grundverhältnis in dem Augenblick um, wo die Einbeziehung in den organisatorischen Staatsverband als rechtmäßige Annexion (oder, bei der gleichgeordneten Integration, als Fusion) zu werten ist. Infolge der zunehmenden Abneigung des Völkerrechts gegen die Annexion ist dieser Punkt heute aber weit hinausgeschoben. So kann es zu einem langen Annexionsprozeß kommen, in dem neben Verträgen auch einseitige Akte des Herrscherstaates die gegenseitigen Beziehungen regeln ${ }^{49}$. Umgekehrt muß ein staatsrechtliches Grundverhältnis ins Völkerrecht umschlagen, sobald die Desintegration mit der Schaffung unabhängiger Staaten ihren Endpunkt erreicht hat. Auch dieser Punkt ist heute manchmal sehr weit hinausgeschoben, so daß auch hier die gegenseitigen Beziehungen nicht nur durch Verträge, sondern auch noch durch einseitige Akte geregelt werden ${ }^{50}$.

4. Die Fremdherrschaft und insbesondere die Kolonialherrschaft wurde bisher nur recht oberflächlich behandelt. In der Tat beschränken sich fast alle Völkerrechtslehrbücher darauf, die einzelnen Protektorate, Mandate und Treuhandschaften nur unter dem Gesichtspunkt zu ordnen, welche völkerrechtlichen Befugnisse der Herrscherstaat übernimmt und inwieweit durch diese Souveränitätsbeschränkungen die Völkerrechtssubjektivität des beherrschten Staates beeinträchtigt wird („halbsouveräne Staaten“). Dabei wird schon die Ausübung der auswärtigen Gewalt durch den Herrscherstaat stark vernachlässigt. Schwerer wiegt aber, daß die inneren Herrschaftsstrukturen nicht erkannt werden. Denn die Begriffe Protektorat, Mandat, Verwaltungszession usw. sind im Gegensatz etwa zu den Begriffen des Einheits- und des Bundesstaates nicht geeignet, Idealtypen der Herrschaft zu bilden. In der Tat können diese einmal unter sich und mit der militärischen Fremdherrschaft, ja selbst den Föderationen ähnliche Herrschaftsstrukturen aufzeigen, zum anderen gibt es innerhalb derselben Gruppe - etwa den Protektoraten - völlig verschiedene Herrschaftsstrukturen. Soweit die Grundakte die Struktur nicht näher bestimmt, hat der Herrscherstaat also einen gewissen Ermessensspielraum für die Regelung des Organisationsverhältnisses.

\footnotetext{
48 Hier sind natürlich nicht die Fälle gemeint, wo etwa auf Grund eines Vertrages bestimmte Gebiete im ganzen die Zuordnung ändern.

49 S. u. II.
} 
Richten wir die Typenbildung nach dem oben eingeführten Begriff der Kompetenzträgerschaft aus, lassen sich der obigen Untersuchung über das Mandatsgebiet Syrien-Libanon, die Kolonien und Protektorate in Indochina und die Kolonien und Treuhandgebiete drei verschiedene Herrschaftstypen entnehmen, welche die bisherigen Lücken der Strukturforschung füllen können. Da hier Organisationsformen der Fremdherrschaft aufgedeckt werden, wird von der Fremdverwaltung gesprochen. Fremdverwaltung ist dabei der Teil des organisatorischen Apparats des Herrscherstaates, der je nach dem Grad der Integration in den Herrscherstaat oder in den beherrschten Staat Hoheitsgewalten des Herrscherstaates, des beherrschten Staates oder eines selbständigen Herrschaftsgebildes ausübt.

a) Der erste Idealtyp der Fremdherrschaftsorganisation ist die in den Herrscherstaat integrierte Fremdverwaltung. Hier handelt es sich zwar meist um in den Staatsverband des Herrscherstaats aufgenommene und deshalb nur politisch fremde Gebiete, doch können auch rechtlich fremde Gebiete erfaßt werden, die trotz ihrer völkerrechtlichen Trennung vom Herrscherstaat im staatsrechtlichen Organisationsverhältnis als Kolonien behandelt werden. Das war im französischen Imperium der Fall bei den Treuhandgebieten Togo und Kamerun, bei den Protektoratsgebieten Indochinas und der zur Verwaltung zedierten chinesischen Provinz Kouang-Tcheou-Wan.

Die Integration im Sinne dieses Herrschaftstyps stellt also die Frage nach dem Staatsverband in einem organisatorischen und nicht im Sinne des Grundverhältnisses. Die Fremdverwaltung ist in den Herrscherstaat integriert, wenn sie und die von ihr ausgeübten Befugnisse im formalrechtlichen Sinne als solche des Herrscherstaates, im französischen Kolonialreich also als „französisch“ erscheinen. Während bei den in den Staatsverband im Sinne des Grundverhältnisses aufgenommenen Territorien auch das Gebiet und seine Bewohner französisch wurden, erstreckte sich bei den außerhalb des französischen Staatsverbands in diesem Sinne stehenden Gebieten diese Qualifikation nur auf die Organisation und deren Befugnisse. Deshalb sprechen wir hier von einer Annexion der Hoheitsbefugnisse („Kompetenzannexion"). Dabei kann sich diese Annexion wie etwa in den Anfängen der Treuhandschaft ${ }^{51}$ auf alle oder wie etwa in den indochinesischen Protektoraten ${ }^{52}$ auf nur einen - allerdings sehr erheblichen - Teil der Hoheitsbefugnisse erstrekken. Da auch bei den A-Mandaten ${ }^{53}$ und den Protektoraten Nordafrikas zumindest die auswärtige Gewalt und die Verteidigung von französischen Organen als französische Hoheitsbefugnisse wahrgenommen wurden, gibt es wohl kaum ein der französischen Kolonialherrschaft unterworfenes Gebiet, in dem man der Teilannexion von Hoheitsgewalten nicht begegnet.

Die Integration der Kolonialgebiete in den Herrschaftsapparat des Mutterlandes befugte dessen Zentralorgane (Präsident der Republik, Regierung, Parlament, Oberste Gerichte) im Rahmen der von Frankreich annektierten Befugnisse zum unmittelbaren Eingriff in diese Gebiete. Organisation und Ausübung der Befugnisse unterlagen also dem französischen Recht einschließlich des Verfassungsrechts. Das bedeutet aber nicht, daß diese Zentralorgane notwendig die gesamte Fremdverwaltung übernahmen. Im Gegenteil führte die räumliche und soziologische Entfernung dieser Gebiete vom Mutterland zu einer sehr weitgehenden organisatori- 
schen Trennung, die im Rahmen der einheitlichen verschiedene Teilrechtsordnungen zuließ, aber immerhin nicht das Ausmaß der im folgenden behandelten Herrschaftstypen erreichte.

Dabei kam es auch vor dem Beginn des Dekolonisierungsprozesses zu interessanten Föderationen. Rein im französischen Bereich blieben die aus mehreren Kolonien in Schwarzafrika und Indochina gebildeten Kolonialunionen. Soweit Frankreich nur einen Teil der Hoheitsbefugnisse für die Republik, die Union und die Kolonien in Anspruch nahm, blieb oder entstand Raum für von einheimischen Staaten getragene Hoheitsbefugnisse. So stand in den indochinesischen Protektoratsgebieten neben der Kolonialunion Indochina und der jeweiligen Kolonie ein einheimischer Staat, standen in Afrika im Laufe des Dekolonisierungsprozesses neben der französischen Republik die neuen Mitgliedstaaten der Gemeinschaft ${ }^{54}$ und die Treuhandstaaten Togo und Kamerun ${ }^{55}$. Diese Staaten konnten wiederum wie die indochinesischen Staaten den französischen Gebietskörperschaften nebenoder wie die atrikanischen und die Treuhandstaaten untergeordnet sein. Bei der Nebenordnung blieb zwischen dem herrschenden und dem beherrschten Staat das Völkerrechtsverhältnis bestehen. In der Tat waren die indochinesischen Staaten zwar nicht mehr voll souverän, doch führte ihre Restsouveränität zur Anwendung der entsprechenden allgemeinen Völkerrechtsregeln auch im Verhältnis zur französischen Republik ${ }^{56}$. Bei der Unterordnung entstanden dagegen bundesstaatsähnliche Gebilde ${ }^{57}$.

b) Das Spiegelbild dieses ersten Typs der Fremdherrschaft ist die in den beherrschten Staat integrierte Fremdverwaltung. Hier übt die Fremdverwaltung einheimische Befugnisse aus. Das kann wiederum in zwei Formen geschehen: Im ersten Fall handelt es sich um eine der Organisation nach rechtlich dem Herrscherstaat zugeordnete Verwaltung, welche entweder aufgrund einer rechtlichen Fiktion oder aufgrund einer ausdrücklichen Delegation durch die Organe des beherrschten Staates dessen Befugnisse wahrnimmt. Eine solche Fiktion finden wir insbesondere bei der alliierten Besetzung Deutschlands ${ }^{58}$. Ausdrückliche Delegationen der staatlichen Hoheitsbefugnisse wurden dagegen in den indochinesischen Protektoraten ${ }^{59}$, aber auch in Marokko und Tunesien benutzt, wo etwa der französische Conseil d'Etat aufgrund paralleler Gesetze Frankreichs und des betreffenden einheimischen Staates über bestimmte einheimische Streitigkeiten entschied ${ }^{60}$. Diese Organleihe ist insbesondere in Indochina nur sehr schwer vom echten Transfer einheimischer Befugnisse auf die französische Republik zu unterscheiden ${ }^{61}$.

\footnotetext{
54 S. $316 \mathrm{ff}$.

55 S. $288 \mathrm{ff}$

56 S. $108 \mathrm{ff}$

57 S. u. II.

58 Zur Theorie der Treuhandschaft, wonach die Alliierten im besetzten Deutschland zumindest auch deutsche Staatsgewalt ausübten, vgl. die von F. Münch a. a. O. zitierten Urteile, die von v. Meister a. a. O zitierte Literatur und M. Rheinstein, The Legal Status of Occupied Germany, Michigan Law Review Bd. 47, 1948/49, S. 23; a. A. E. Kaufmann a. a. O.; G. Jaenidke a. a. O., S. 12; R. Stödter, Deutschlands Rechtslage, 1948 , S. $137 \mathrm{ff}$

59 S. $92 \mathrm{ff} ., 95 \mathrm{ff}$.

60 Für Tunesien entschied der Conseil d'Etat auf Grund eines französischen Dekrets vom 31.1 . 1927 und eines "décret beylical“ vom 10. 11. 1926, für Marokko auf Grund eines französischen Dekretes vom

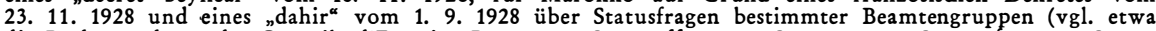
die Rechtsprechung des Conseils d'Etat in: Rec. 1945, S. 289 ff.; 1946, S. 352; 1947, S. 535 f.; 1948 , S. 539 f.; 1950, S. $699 \mathrm{ff} . ; 1951$, S. $661 \mathrm{f.;} 1953$, S. 626).

61 S. $92 \mathrm{ff}$., $95 \mathrm{ff}$.
} 
Eine völlige Integration in den beherrschten Staat finden wir dort, wo die Fremdverwaltung nicht nur einheimische Hoheitsgewalt ausübt, sondern auch selbst formalrechtlich dem beherrschten Staat zugerechnet wird. Dabei kann auch diese Zurechnung wieder mehr oder weniger fingiert sein, kann es sich ferner um die Integration ganzer Verwaltungszweige oder nur einzelner Beamter handeln. So übten nach der Auffassung des Conseil d'Etat die französischen Behörden und Beamten in Marokko und Tunesien nicht nur einheimische Hoheitsgewalt aus, soweit sie für Rechnung und im Interesse des protegierten Staates und seiner Bevölkerung handelten ${ }^{62}$, sondern wurden sie auch als marokkanische und tunesische Behörden, ihre Angehörigen als marokkanische und tunesische Beamte angesehen, für deren Handlungen der französische Staat nicht haftete, für deren Statusstreitigkeiten der Rat nicht zuständig war, deren Entscheidungen vor dem Rat nicht angefochten werden konnten ${ }^{63}$. Besonders häufig treffen wir die organisatorische Integration auch bei der Kontrolle der Tätigkeit der einheimischen Staaten, die etwa in Indochina ganz durch einheimisches Recht geregelt war ${ }^{64}$.

Im Gegensatz zur Fiktion der Treuhandschaft haben bei der Delegation einheimischer Hoheitsgewalt an Organe des Herrscherstaates und bei der völligen Integration der Fremdverwaltung in den beherrschten Staat die betreffenden Behörden, Gerichte und Beamten das materielle und das Verfahrensrecht des einheimischen Staates anzuwenden; bei der völligen Integration ergreift das einheimische Recht auch die Organisation der Fremdverwaltung. Werden diese beiden Techniken auf einem bestimmten Gebiet allgemein angewendet, bleibt die rechtliche und organisatorische Einheit des beherrschten Staates formal also völlig intakt. Deshalb bleiben auch alle Rechtsbeziehungen zwischen dem herrschenden und dem beherrschten Staat auf der Ebene des Völkerrechts. Im Gegensatz zur Organ- und Beamtenleihe in den nachkolonialen Kooperationsverhältnissen benutzte der Herrscherstaat hier aber zwei Mittel, um dem beherrschten Staat seinen Willen aufzuzwingen: Einmal war der gesamte Staatsapparat der „dirigistischen“ Kontrolle des Herrscherstaates unterworfen, zum anderen unterstanden die französischen Beamten und Behörden im Endergebnis nur den Weisungen ihrer Mutterverwaltungen („Herrschaft durch innerdienstliche Weisung“). Im Gegensatz zur formalrechtlichen wurde also die politische Einheit des beherrschten Staates völlig zerbrochen, bildete die Fremdverwaltung einen unter fremder Hierarchie stehenden „Staat im Staate“, der im Ergebnis das Geschick des Gebietes bestimmte. Dabei trat häufig auch das Phänomen einer Überlagerung der formellen durch eine informelle Hierarchie auf, wie wir sie auch in anderen Fällen, etwa bei dem Auftreten der Résistance in Indochina ${ }^{65}$ oder in totalitären Staaten kennen, wenn die eigentliche Macht außerhalb der formellen Hierarchie steht.

c) Der dritte Typ der Fremdherrschaft ist die formalrechtlich sowohl vom Herrscherstaat als auch vom beherrschten Staat getrennte und deshalb selbständige Fremdverwaltung. Dieser Typ entwickelt sich wohl nur bei rechtlich fremden

62 Diese Formel sollte die ihrer Natur nach einheimischen Befugnisse abgrenzen und erfaßte beinahe die gesamte Tätigkeit der Fremdverwaltung.

63 Vgl. Conseil d'Etat 21. 2. 1947 Bessis, Rec. S. 65; 18. 4. 1947 Lemaigre Dubreuil, Rec. S. 149; 10.12 .1947 1950, S. 699 ff.; 1951, S. 661 f.; 1953, S. 626).

Dannaut, Rec. S. 535; 24. 3. 1954 Langue, Rec. S. 180; 27. 6. 1951 Baillard, Rec. S. 370; 21.11 .1956 Rolland, Rec. S. 605; 30. 11. 1956, Serfa ty, Rec. S. 605; 28. 6. 1957 Rion, Rec. S. 423 ; 28.1 .1959 Sliman Bey, Rec. S. 745.

64 S. $101 \mathrm{ff}$.

65 S. $113 \mathrm{ff}$. 
Gebieten und soll deren Trennung vom Herrscherstaat unterstreichen. Im Kolonialrecht ziemlich selten, stellt er wohl den Prototyp der militärischen Fremdverwaltung dar. Hier werden die Hoheitsbefugnisse über das beherrschte Gebiet zunächst der Außen- oder Militärgewalt des Herrscherstaates zugeordnet. Diese Befugnisse werden von der Exekutive ausgeübt und sind regelmäßig gegen eine Einwirkung der anderen Zentralorgane des Herrscherstaates, insbesondere seines Parlaments und seiner Gerichte ${ }^{66}$ stark abgeschirmt. Meist begnügt sich die Exekutive darüber hinaus damit, den an der Spitze der Fremdverwaltung stehenden Beamten oder Offizier zu ernennen und ihm alle Organisations- und Hoheitsbefugnisse auf dem betreffenden Gebiet anzuvertrauen. Deshalb erscheint die Fremdverwaltung im Ergebnis auch von der äußeren oder Militärgewalt des Herrscherstaates so weit getrennt, daß ihre Behörden nicht mehr als Organe, ihre Befugnisse nicht mehr als solche des Herrscherstaates erscheinen und insbesondere nicht mehr der Verfassung ${ }^{67}$ und den Gesetzen des Heimatstaates unterworfen sind.

Im französischen Rechtskreis wurde diese organisatorische und rechtliche Trennung des beherrschten Gebiets vom Mutterland im A-Mandat Syrien und Libanon entwickelt; die französischen Behörden, welche die Mandatsbefugnisse ausübten, wurden deshalb vom Conseil d'Etat nicht mehr als „französisch“ angesehen ${ }^{68}$. Auf dieses Vorbild stützt sich die Organisation der Fremdverwaltung im besetzten Deutschland. Auch hier beschränkte sich die französische Republik darauf, zwecks Ausführung der internationalen Akte durch ein Dekret vom 15. Juni 1945 ein "commandement en chef chargé d'assurer l'exercice du gouvernement sur les territoires allemands occupés par les forces françaises" $\mathrm{zu}$ begründen ${ }^{69}$. Im Anschluß an seine Rechtsprechung über die Zurechnung der Fremdverwaltung im A-Mandat Syrien/Libanon ${ }^{70}$ prïfte deshalb der Conseil d'Etat, ob das konkrete Handeln der Fremdverwaltung Ausübung französischer Staatsgewalt war oder ob es sich seinem Gegenstand nach „rattache au gouvernment de l'Allemagne"71. Im zweiten Fall wurde die Militärverwaltung nicht als „autorité de l'Etat français“, sondern als "autorité étrangère" angesehen, für die der französische Staat nicht haftet und gegen deren Entscheidungen eine Klage vor dem Rat nicht zulässig ist ${ }^{72}$. Dieselbe Auffassung vertrat der Conseil d'Etat für die französische Militärverwaltung in Ósterreich ${ }^{73}$. Im Gegensatz zu seinem Regierungskommissar Jacomet $^{74}$ hat es der französische Staatsrat mit seiner vorsichtigen Formulierung stets vermieden, die Treuhandtheorie anzuerkennen.

$66 \mathrm{Vgl}$. die Stichworte „actes de gouvernement, actes politiques, actes de souveraineté, acts of State, political acts, Regierungsakte, sovereign power" im Sachregister zu: Die Haftung des Staates für rechtswidriges Verhalten seiner Organe. Länderberichte und Rechtsvergleichung, Beiträge zum ausländischen öffentlichen Recht und Völkerrecht, 44, 1967.

$67 \mathrm{Vgl}$. die von $\mathbb{W}$. O'Brien, The Constitution of the United States and the Occupation of Germany, World Polity, Bd. 1, 1957, S. 61 zitierte amerikanische Rechtsprechung.

$68 \mathrm{~S} .42 \mathrm{ff}$

69 Dekret vom 15. 6. 1945 (JORF 27. 6. 1945, S. 3891).

70 So sehr klar die Ausführungen des Regierungskommissars Jacomet unter Conseil d'Etat 10. 7. 1955 Kelm, Rec. S. 469.

71 Auch hier wurde also versucht, die ihrem Wesen nach "deutschen“ von den ihrem Wesen nach "französischen " Hoheitsgewalten zu unterscheiden.

72 Conseil d'Etat 29. 6. 1951 Bonduelle, Rec. S. $376=$ JCP 1952 II, 1032 Anm. Virally; 21. 12. 1951 Korette, Rec. S. 603; 21. 11. 1952 Association pour la reconstruction à Paris et Metz du monument du Général Mangen, Rec. S. 520; 15. 12. 1954 Roucaute, Rec. S. 663; 10. 7. 1955 Kelm, Rec. S. 469; 21. 12. 1955 Société des Etablissements Kienzle Uhrenfabrik, RDP 1956, S. 1009; 10. 7. 1957 Société Saarländische Lederwerke, Rec. S. 455; 16. 4. 1958 Schweigert, Rec. S. 808; 20. 1. 1961 Ministre de l'agriculture c. Cie générale des parquets et menuiseries, Rec. S. 901; vgl. auch O. Debbasch, L'occupation militaire, 1962, S. $251 \mathrm{ff}$.

73 Conseil d'Etat 24. 2. 1956 Riefenstahl, Rec. S. 605; 30. 11. 1962 Compagnie de développement agricole et industrielle, Rec. S. 644. Im letzten Fall untersucht der Rat, in welchem Namen und für wessen Rechnung die Fremdverwaltung im internationalen Bereich gehandelt hat und sieht als wesentliches Kriterium an, ob Osterreich durch die betreffenden völkerrechtlichen Verträge gebunden war oder nicht.

74 Jacomet vertritt a. a. O. die Auffassung, die Besatzungsmacht habe "fusionierte* einheimische deutsche und französische Souveränität ausgeübt. 
Auf der anderen Seite sind bei diesem Typ die Organisation und die Befugnisse der Fremdverwaltung formell auch nicht von der einheimischen Rechtsordnung abzuleiten; es handelt sich - und hierin liegt der Unterschied zur in den beherrschten Staat integrierten Fremdverwaltung - auch im Verhältnis zum beherrschten Staat, sofern ein solcher überhaupt existiert, um "fremde“ Behörden" ${ }^{75}$. Damit stellt sich die Frage, wer denn nun eigentlich der Träger dieser Befugnisse ist. Nur in den seltensten Fällen wird man dabei die Fiktion aufstellen können, es handle sich um Befugnisse des besetzten Staates. So bleibt nur die Möglichkeit, der Fremdverwaltung selbst zumindest nach innen eine selbständige, das heißt aber eine zwar vom Herrscherstaat oder dritten Staaten begründete, diesen Staaten aber nicht unter- und eingeordnete Rechtssubjektivität zuzusprechen. Dabei wird es sich meist um staatsähnliche Gebilde sui generis handeln ${ }^{76}$. Es gibt aber auch die Möglichkeit, die Fremdverwaltung selbst als Staat zu etablieren. Dieses Modell finden wir etwa im belgischen Kongo bis 190877, wurde aber auch — allerdings ohne Rechtsgrundlage - für die Indochinesische Föderation ${ }^{78}$ und für CochinChina ${ }^{79}$ vorübergehend benutzt.

Auch bei diesem Herrschaftstyp kann die Fremdverwaltung einem oder mehreren einheimischen Staaten übergeordnet sein, so daß wiederum bundesstaatsähnliche Gebilde entstehen. Solche Konstruktionen finden wir im besetzten Deutschland und Österreich, aber auch im A-Mandat Syrien/Libanon ${ }^{80}$.

5. Bei den genannten drei Formen der Fremdverwaltung handelt es sich um Idealtypen; in der konkreten Fremdherrschaft können also zwei oder drei dieser Formen nebeneinander auftreten. Dabei werden regelmäßig die Hoheitsbefugnisse auf die verschiedenen Fremdverwaltungen aufgeteilt. So wurden in Syrien und im Libanon etwa die inneren Hoheitsrechte als solche des A-Mandats von einer selbständigen Fremdverwaltung, die äußeren als französische Befugnisse unmittelbar von den zuständigen Organen der französischen Republik ausgeübt. In den indochinesischen Protektoraten waren die Hoheitsbefugnisse grundsätzlich zwischen der französischen Republik und den einheimischen Staaten aufgeteilt; die französischen Hoheitsbefugnisse wurden entweder von den Zentralorganen der französischen Republik oder von den in den Herrscherstaat integrierten Kolonialunionen und Kolonien wahrgenommen, die einheimischen Hoheitsbefugnisse von den Organen der einheimischen Staaten, in die aber zwecks Kontrolle und vereinzelt auch zwecks Ausübung bestimmter Hoheitsbefugnisse französische Beamte integriert waren.

6. Kurz eingegangen werden soll hier auch auf die Fremdherrschaftskonkurrenz. Dabei können mehrere Herrschaftsstaaten oder mehrere Fremdverwaltungen desselben Herrschaftsstaats die Herrschaft über ein dem Grundverhältnis nach einheitliches Gebiet oder dieselbe Fremdverwaltung die Herrschaft über mehrere dem

75 So der Conseil d'Etat in seiner Entscheidung Société des Grands magasins du Louvre vom 23. 12.1947 (Rec. S. 495) für die deutschen Besatzungsbehörden in Frankreich. Zu demselben Ergebnis kommen auch die Autoren, welche die Treuhandtheorie für das besetzte Deutschland ablehnen.

$76 \mathrm{Das}$ war sicherlich beim A-Mandat Syrien/Libanon der Fall (S. $40 \mathrm{ff}$., $42 \mathrm{ff}$.). Eine ähnliche Konstruktion versucht der Conseil d'Etat wohl, wenn er im Urteil Schweigert (s. o.) ausführt, der Hochkommissar habe "dans l'exercice d'attributions à lui conférées par le Conseil de la Haute Commission alliée, organisme international“ gehandelt oder im Urteil Riefenstahl (s. o.), die „Commissions militaires alliées exercent l'autorité suprême en Autriche“.

77 Vgl. neuerdings J. P. de Bandt, De quelques problèmes de succession d'Etat à la suite de l'accession à l'indépendance de la République du Congo (Léopoldville), Revue belge de droit international, 1965, S. 497.

78 S. $133 \mathrm{ff}$.

80 S. $42 \mathrm{ff} ., 45 \mathrm{ff}$. 
Grundverhältnis nach rechtlich getrennte Gebiete besitzen. Das Organisationsverhältnis der Fremdherrschaftskonkurrenz kann also dem Grundverhältnis nach einheitliche Gebiete in mehrere selbständige Teile spalten (Aufteilung Deutschlands und Osterreichs in vier, Frankreichs in zwei Besatzungszonen, Marokkos in das französische und das spanische Protektorat, Viêt-Nams in die beiden französischen Protektorate Annam und Tongking und die Kolonie Cochin-China) oder mehrere dem Grundverhältnis nach getrennte Gebiete zusammenfügen ( $\mathrm{Zu}$ sammenfassung der Protektorats- und Kolonialgebiete Indochinas sowie der chinesischen Südprovinz in die Indochinesische Föderation). Hier entstehen mehrere sich überlagernde Rechtsschichten, die jeweils verschiedene Rechtseinheiten ausbilden, so daß im Einzelfall geprüft werden muß, welcher Einheitsbegriff zugrunde $\mathrm{zu}$ legen ist ${ }^{81}$.

Bei der Konkurrenz mehrerer Herrschaftsstaaten können ähnliche oder verschiedene Herrschaftstitel vorliegen. Es können so zwei oder mehrere koloniale (spanisches und französisches Protektorat über Marokko, französisch-englisches Kondominium über die neuen Hebriden) oder militärische (vier Besatzungsmächte in Osterreich und Deutschland, zwei Besatzungsmächte in Frankreich) Fremdherrschaften zusammentreffen oder aber auch eine koloniale mit einer militärischen Fremdherrschaft (britische Besatzungsmacht und französische Kolonialherrschaft in Syrien/Libanon ${ }^{82}$ sowie in Indochina) ${ }^{83}$. Dabei können die Herrschaftsstaaten voneinander abgeleitete (spanisches Protektorat in Marokko vom französischen Protektorat, belgische von der englischen Besatzung in Deutschland) oder selbständige Herrschaftstitel besitzen. Ferner können die Herrschaftsstaaten alle oder einen Teil der Befugnisse gemeinsam oder nach der Art der Hoheitsbefugnisse oder nach dem Gebiet getrennt ausüben; bei der gemeinsamen Ausübung sind wiederum verschiedene Staatenverbindungen möglich, die bei der militärischen Fremdherrschaft auch von der Art der gemeinsamen Befehlsstruktur der alliierten Armeen abhängen können.

Besondere Rechtslagen entstehen bei der militärischen Besetzung eines Gebiets, das unter der Kolonialherrschaft des dort besiegten Staates steht. Hier wird die Fremdverwaltung ausgewechselt. Die Kolonialordnung gilt dagegen weiter, wird aber von der Ordnung der Besatzungsmacht überlagert (französische Besetzung Togos und Kameruns $s^{84}$, japanische Besetzung Indochinas) ${ }^{85}$. Immer besteht aber die Tendenz, die eigene Fremdverwaltung endgültig an die Stelle der Fremdverwaltung des unterlegenen Staates zu setzen, die militärische Besetzung der fremden Kolonie also in eine eigene Kolonialherrschaft $\mathrm{zu}$ verwandeln. Auch hier können sich mehrstufige Fremdverwaltungen zeigen. So wurde Indochina unter britischem Oberbefehl 1945 von Großbritannien und Frankreich besetzt, die noch existierende japanische Militärverwaltung aber zur Ausübung bestimmter Sicherungsfunktionen ermächtigt ${ }^{86}$. Hier trafen also die englische und französische Militärherrschaft, die japanische Militärherrschaft und die französische Kolonialherrschaft in einem sehr schwer zu entwirrenden Verhältnis zusammen.

81 Zur durch den Herrscherstaat geschaffenen Einheit im Organisationsverhältnis S. 45 ff., $106 \mathrm{ff}$.

82 S. $50 \mathrm{ff}$.

83 S. $123 \mathrm{ff}$

84 S. $242 \mathrm{ff}$.

85 S. $112 \mathrm{ff}$.

86 S. $112 \mathrm{ff}$ 


\section{Der Unabhängigkeitsprozeß}

1. Die Dekolonisierung ist ein Prozeß, an dessen Anfang die Kolonialherrschaft und an dessen Ende die Unabhängigkeit der abhängigen Gebiete steht.

a) Der Begriff der Dekolonisierung hat nach der ideologischen Ausrichtung des Benutzers einen verschiedenen Inhalt. Diese Unterschiede sind in voneinander abweichenden Definitionen des Kolonialphänomens begründet, die notwendig nicht nur den Anfangs-, sondern auch den Endpunkt der Entwicklung bestimmen. Denn die Dekolonisierung hat eben ihr Ziel noch nicht erreicht, wenn eine bestimmte, vom Mutterland als Endpunkt gedachte Rechtslage am kolonialen Phänomen noch teilhat.

Nach Ansicht der meisten Kolonialstaaten besteht das Wesen des kolonialen Phänomens in der strukturellen rechtlichen Ungleichheit zwischen der Bevölkerung der Kolonien und der des Mutterlandes, die sowohl auf der Ebene des Individuums als auch auf der Ebene der Sozialgruppen ihren Ausdruck findet. Die Dekolonisierung ist deshalb

" un procéssus d'établissement ou de rétablissement du droit commun, sur une base strictement égalitaire, dans les rapports inter-individuels et intercollectifs entre anciens colonisateurs et anciens colonisés » ${ }^{\mathbf{8 7}}$

und kann folglich nicht nur in der Unabhängigkeit der Kolonien, sondern auch in der völligen, das heißt aber rechtlich gleichgeordneten Assimilation an die Bevölkerung des Mutterlandes, das heißt der rechtlich gleichgeordneten Integration in das Mutterland bestehen ${ }^{88}$.

Nach der Ansicht des Ostblocks und der afrikanisch-asiatischen Staaten, die in der Resolution der UN-Vollversammlung vom 14. Dezember $1960^{89}$ einen wenn auch recht unklaren Ausdruck fand ${ }^{90}$, kann die Dekolonisierung nur mit der völligen Unabhängigkeit der Kolonien enden; die revolutionäre" verlangt darüber hinaus im Gegensatz zu der "gemäßigten“ Richtung den Abbau des Neo-Kolonialismus, d. h. aber der politischen und insbesondere wirtschaftlichen Beherrschung ${ }^{91}$.

Beide Definitionen der Dekolonisierung benutzen rein objektive Kriterien der endgültigen Rechtslage. Das bedeutet aber, daß ihnen das Selbstbestimmungsrecht entweder überhaupt nicht oder doch in einem ebenfalls objektivierten Sinne zugrunde liegt. Das Selbstbestimmungsrecht wird also entweder als das Recht zur Selbstregierung verstanden ${ }^{92}$ oder es wird, soweit die Statusbestimmung in den Vordergrund rückt, eine mehr oder weniger unwiderlegliche Vermutung für den

$87 \mathrm{Vgl.} \mathrm{J.} \mathrm{L.} \mathrm{Quermonne,} \mathrm{Esquisse} \mathrm{d'une} \mathrm{théorie} \mathrm{juridique} \mathrm{et} \mathrm{politique} \mathrm{de} \mathrm{la} \mathrm{décolonisation,} \mathrm{RJPUF} \mathrm{1958,}$ S. 429 ff., 437; ebenso M. Gharsallah, Réflexions sur la décolonisation. Notions juridique, politique et économique, RJPOM 1963, S. 235.

88 So ausdrücklich Quermonne a. a. O., S. $445 \mathrm{ff}$.

89 Resolution 1514 (XV). Hierzu vgl. A. Coret, La déclaration de l'Assemblée générale de l'O. N. U. sur l'octroi de l'indépendance aux pays et aux peuples coloniaux, RJPUF 1961, S. 586.

90 In der Tat unterstreicht die Resolution das Recht der Völker auf die Bestimmung ihres Statuts, hebt aber andererseits mehrfach hervor, daß die Dekolonisierung nur mit der Unabhängigkeit enden könne. Etwas klarer für die Selbstbestimmung im Sinne der Statusbestimmung jeweils Art. 1 Abs. 1 des Draft Convenant on economic, social and cultural rights und des Draft Convenant on Civil and Political Rights (A 6342 vom 19. 7. 1966).

$91 \mathrm{Vgl}$. hierzu Kwame Nkrumah, Neo-Colonialism, The Last Stage of Imperialism, 1966.

92 Vgl. die Präambel der genannten UN-Resolution: "Convinced that all peoples have an inalienable right to complete freedom, the exercise of their sovereignty and the integrity of their national territory" Art. 1: The subjection of peoples to alien subjugation, domination and exploitation constitutes a denial of fundamental rights, is contrary to the Charter of the United Nations and is an impediment to the promotion of world peace and co-operation." 
Willen der jeweiligen Bevölkerung zur Unabhängigkeit aufgestellt $t^{93}$. Dekolonisierung ist also die Durchsetzung eines objektiven Prinzips. Diese Auffassung liefert in der Tat den Schlüssel für das Verhältnis der Dekolonisierung zum Selbstbestimmungsrecht. Wie alle sozialen Erscheinungen ${ }^{94}$ wird auch die Dekolonisierung zwar von den Beteiligten getragen, folgt aber eigenen Gesetzen und zwingt sich ihren Willen auf. Soweit in der Dekolonisierungspraxis auf den tatsächlichen Willen der Bevölkerung oder seiner Repräsentationen zurückgegangen wird, zeigt sich in der Tat, daß diese sich auf die Dauer gegen die Sprengkraft der neuen Ideologie nicht abschirmen können, so daß die unterhalb der Unabhängigkeit bleibenden Rechtslagen, selbst wenn sie von der Kolonialbevölkerung ebenso wie vom Mutterland zunächst als endgültig gewollt sind, sich sehr bald nur als Übergangsperioden herausstellen. Nach einer ersten Initialzündung scheint so jeweils in einer bestimmten Region ein fast automatischer Desintegrationsprozeß abzulaufen, dem sich eine einzelne Kolonie schon deshalb nicht entziehen kann, weil ihre Repräsentanten sonst als „Neo-Kolonialisten“ innerhalb dieser Region und auf der afro-asiatischen Ebene einen sehr schwierigen Stand hätten.

Die Dekolonisierung ist also ein objektives Ordnungsprinzip, das als „idée-force“ $\mathrm{zu}$ einer Neuverteilung der Welt führt. Es hat damit nicht nur dieselbe Wirkung wie das Nationalstaatsprinzip im Europa des 19. und beginnenden 20. Jahrhunderts, sondern stellt sich als Durchsetzung eben dieses Prinzips im außereuropäischen Raum dar. Diese Verwirklichung in je abgeschlossenen Räumen ist auch dem Dekolonisierungsprozeß selbst eigen. Denn auch dieser Prozeß vollzog sich jeweils mit Bezug auf bestimmte Regionen: Ende des 18. Jahrhunderts in Nordamerika, Anfang des 19. Jahrhunderts in Südamerika, nach 1945 zunächst in Südostasien, dann in Nordafrika und schließlich in Schwarzafrika, während die Restkolonien etwa in Mittelamerika und im nördlichen Südamerika noch heute im wesentlichen unangefochten sind.

Der Ableitung der Dekolonisierung aus dem Nationalstaatsgedanken wird man entgegenhalten, daß die neuen Staaten bisher nur in den seltensten Fällen auf einer Nation aufbauen. Dieses Argument verkennt aber, daß das Nationalstaatsprinzip neben der positiven eine negative Seite besitzt. In der Tat verlangt dieser Grundsatz die Kongruenz von Staat und Nation. Die Bevölkerung, die außerhalb der Nation steht, muß also entweder in diese einbezogen oder auch rechtlich ausgeschieden, also in einem unabhängigen Staat vereinigt werden. Wie schon die Aufteilung Österreichs und die Sezession der südamerikanischen Staaten zeigt, braucht diesem neuen Staat zu diesem Zeitpunkt noch keine Nation zu entsprechen, wenn er sich nur die Schaffung einer solchen Nation zum Ziele setzt.

Im Gegensatz zu den beiden obigen Definitionen verlangt die Dekolonisierung also entweder das Aufgehen der Kolonialbevölkerung in der Nation des Mutterlandes oder die Bildung einer neuen Nation in einem und durch einen neuen, unabhängigen Staat. Dabei kann die rechtliche Integration in das Mutterland der erste

93 Vgl. die Präambel der genannten UN-Resolution: „Recognizing the passionate yearning for freedom in all dependent peoples and the decisive role of such peoples in the attainment of independence... Recognizing that the peoples of the world ardently desire the end of colonialism in all its manifestations... Believing that the process of liberation is irresistible and irreversible and that, in order to avoid serious crises, an end must be put to colonialism and all practices of segretation and discrimination associated therewith, Welcoming the emergence in recent years of a large number of dependent countries into freedom and independence, and recognizing the increasingly powerful trends towards freedom in such territories which have not yet attained independence $\cdot \dot{\text { « }}$ So schon E. Durkheim, Regeln der soziologischen Methode, Soziologische Texte, Bd. 3, 1965. 
Schritt zu einer Integration in die Nation darstellen. Eine solche Integration benötigt aber so viel Zeit, daß angesichts der Ungeduld der afro-asiatischen Staaten die Unabhängigkeit das typische Ende des Dekolonisierungsprozesses darstellt.

b) Im Gegensatz zu den Sezessionen des vorigen Jahrhunderts stellt sich die nach dem zweiten Weltkrieg einsetzende Dekolonisierung nicht mehr als einseitige Losreißung vom Mutterland, sondern als ein mehr oder weniger auf gegenseitigem Einverständnis beruhender, kontinuierlicher Prozeß94a dar, der von der absoluten Kolonialherrschaft über mehrere Phasen oder Stufen zur Unabhängigkeit führt. Der Dekolonisierungsprozeß ist damit dem Annexions-95 und dem modernen Integrationsprozeß umgekehrt parallel ${ }^{96}$. Er unterscheidet sich vom letzteren insoweit, als das Ziel und die diesem Ziel entgegenstrebenden Stufen nur selten und auch dann nur partiell in einem einheitlichen rechtlichen oder auch nur politischen Programm niedergelegt sind ${ }^{97}$, sondern von Stufe $\mathrm{zu}$ Stufe unter meist großen rechtlichen und politischen Schwierigkeiten neu festgesetzt wurden. Im französischen Rechtsraum enthalten so die Verfassungen von 1946 und 1958 zwar verschiedene Statuskategorien und regeln sie die Akte, kraft welcher ein Gebiet von der einen in die andere Kategorie gehoben werden konnte, doch handelte es sich hier immer nur um Möglichkeiten und nicht um ein Programm der Entwicklung. Außerdem wurden diese rechtlichen Möglichkeiten darüber hinaus immer wieder von der politischen Entwicklung überrollt.

2. Obwohl die verschiedenen Phasen des Dekolonisierungsprozesses in den einzelnen Gebieten so unterschiedliche rechtliche Strukturen aufweisen, daß eine Klassifizierung und Typenbildung kaum möglich erscheint, lassen sich doch die allgemeine Tendenz und bestimmte Elemente der Entwicklung herausarbeiten: Der allmählichen Umstellung der politischen Machtverhältnisse von der Einheit zur Mehrheit von Entscheidungszentren entspricht eine fortschreitende Anpassung auch der rechtlichen Strukturen vom subordinations- an den koordinationsrechtlichen Typus, eine allmähliche Verdrängung der staats- durch völkerrechtliche Elemente, bis im Endzustand die einzelnen Materien nach ihren Rechtsquellen und deren Inhalt so geregelt sind, wie es im Verhältnis zwischen unabhängigen Staaten üblich ist. Da bei der Integration der Fremdverwaltung in den beherrschten Staat dieser formell die volle Souveränität behält, zeigt sich diese Wandlung der formalen Strukturen auch im Dekolonisierungsprozeß natürlich nur bei den beiden anderen Typen der Fremdverwaltung.

a) Die erste Voraussetzung einer solchen Entwicklung ist die Existenz einheimischer Staaten. Soweit nicht wie in Indochina, Marokko und Tunesien an auch während der Kolonialherrschaft weiterbestehende und modernisierte Staaten angeknüpft werden konnte, mußte das Mutterland diese Staaten entweder durch einen Akt der französischen Republik ${ }^{98}$ oder der Fremdverwaltung ${ }^{99}$ schaffen oder doch

\footnotetext{
94a Vgl. E. Kordt a. a. O. und M. Merle, La décolonisation, Annales de la Faculté de Droit de Liège, 1966, S. 33 ff., ferner die Präambel der zitierten UN-Resolution (Anm. 93).

$95 \mathrm{Vgl}$. die Entwicklung in Indochina bis 1945, S. $110 \mathrm{ff}$

96 Dabei ist natürlich zu berücksichtigen, daß dieser Integrationsprozeß nicht zu einer untergeordneten, sondern zu einer nebengeordneten Integration führen soll.

97 Für Togo und Kamerun S. 390. In Schwarzafrika war durch die franz. Verfassung von 1958 und in den Togo- und Kamerunakten das Selbstbestimmungsrecht anerkannt.

$98 \mathrm{Vgl}$. die Gründung der Republiken Togo und Kamerun (S. $288 \mathrm{ff}$.).

99 Vgl. die Gründung der verschiedenen Staaten im Mandatsgebiet Syrien/Libanon (S. 19 ff.).
} 
in einem allgemeinen Akt die Staatsgründung durch einheimische Organe erlauben ${ }^{100}$ und $\mathrm{zu}$ diesem Zweck zunächst einen Teil der Befugnisse auf in manchen Strukturen Staatsorganen ähnelnde Organe der Überseeterritorien überleiten ${ }^{101}$.

b) Auch die Verfassung dieser Staaten wurde teils heteronom ${ }^{102}$, teils autonom ${ }^{103}$ gesetzt. Dabei hatte aber der jeweils nicht zur Verfassunggebung berufene Staat häufig so starke Mitwirkungsrechte, daß diese Disjunktion weitgehend ihre Bedeutung verlor ${ }^{104}$. Auch konnte das Recht zur Änderung der heteronomen Verfassung bei der Fremdverwaltung bleiben, auf den beherrschten Staat übergehen oder konkurrierend ausgeübt werden ${ }^{105}$, der Fremdverwaltung der die Verfassung durchbrechende Eingriff in das innere Verfassungsleben völlig ${ }^{106}$ oder nur zum Zwecke seiner Wiederherstellung und der Sicherung der öffentlichen Ordnung ${ }^{107}$ offen stehen oder schließlich ganz verboten sein.

$\mathrm{Da}$ die Befugnisse der Fremdverwaltung nicht in den lokalen Verfassungen, sondern entweder (wie auch bei der militärischen Fremdverwaltung) im Völkerrecht oder (wie auch beim Bundesstaat) in der übergeordneten Verfassung des umgreifenden französischen Staatsverbandes verankert waren, brauchten die einheimischen Verfassungen sie grundsätzlich weder ausdrücklich aufzuführen noch vorzubehalten. Dennoch legten sich die lokalen Verfassungen meist gewisse Beschränkungen auf, um jeden Anschein einer Usurpation von Befugnissen der Fremdverwaltung zu vermeiden. Dabei wurden die Kompetenzen der Fremdverwaltung entweder ausdrücklich oder durch den Hinweis auf die Zugehörigkeit des einheimischen Staates zur französischen Union, indochinesischen Föderation oder französischen Gemeinschaft unmittelbar vorbehalten; außerdem begründeten die Verfassungen grundsätzlich nur solche Organe und wiesen diesen nur die Befugnisse zu, die dem jeweiligen Status des betreffenden Staates entsprachen ${ }^{108}$; damit entstand bei jeder Phase des Unabhängigkeitsprozesses die Notwendigkeit einer Verfassungsangleichung.

c) $\mathrm{Da}$ die Fremdverwaltung und der beherrschte Staat Hoheitsgewalt auf demselben Territorium ausübten, mußten in jeder Phase ihre jeweiligen Herrschaftsbereiche festgelegt werden. Das geschah bei der formellen Nebenordnung von Herrscher- und beherrschtem Staat (indochinesische Protektorate) durch Vertrag, bei den Subordinationsverhältnissen in Schwarzafrika zunächst durch einseitige französische Akte (Verfassung, Dekret, Ordonnanzen), an dem aber auch die einheimischen Staaten oder ihre Bevölkerung schon stark beteiligt waren, bis in einer zweiten Phase noch vor der Unabhängigkeit auch hier ein Vertrag vorgeschaltet wurde ${ }^{109}$ oder sogar neben den einseitigen Akt trat ${ }^{110}$. Wie beim Integrationsprozeß

$100 \mathrm{Vgl}$. die Gründung der Mitgliedstaaten der französischen Gemeinschaft (S. 316 ff.).

$101 \mathrm{Vgl}$. die Entwicklung der "territoires d'outre-mer “ (S. $267 \mathrm{ff} ., 280 \mathrm{ff}$.).

102 So die Verfassungen Syriens und des Libanon (S. $29 \mathrm{ff}$.) und die Ửergangsverfassungen Togos und Kameruns (S. $288 \mathrm{ff} ., 290 \mathrm{ff}$.).

103 So die indochinesischen Verfassungen nach 1946 (S. 125 ff.) und die Verfassungen der Mitgliedstaaten der Gemeinschaft (S. $316 \mathrm{ff}$.).

104 So wurde die libanesische Verfassung von der einheimischen Konstituante verabschiedet und vom Hochkommissar promulgiert, die syrische Verfassung von der einheimischen Versammlung ausgearbeitet und vom Hochkommissar in Kraft gesetzt (S. 29). Die Verfassungen Togos und Kameruns ergingen zunächst nach Anhörung der Territorialversammlungen, später auf Grund eines bilateralen Vertrages.

$105 \mathrm{Zur}$ Konkurrenz vgl. Syrien und Libanon (S. $29 \mathrm{ff}$.).

106 So in Syrien und im Libanon (S. $20 \mathrm{ff}$., $29 \mathrm{f}$.).

107 "Abwicklungsverhältnis “ in Syrien und Libanon (S. $72 \mathrm{ff}$.); Togo und Kamerun (S. $305 \mathrm{ff}$.)

$108 \mathrm{Zu}$ diesen Problemen und insbesondere zur Usurpation von Herrschaftsbefugnissen durch Verfassungsänderung vgl. Syrien und Libanon (S. $26 \mathrm{f.,} 59 \mathrm{ff}$.), Indochina (S. $118 \mathrm{ff} ., 144 \mathrm{ff}$.) und die französische Gemeinschaft (S. 318 f.)

109 Togo und Kamerun (S. 298).

110 Togo und Kamerun (S. 298 ff.). 
manchmal der Vertrag in eine Verfassung, wurde hier selbst der einseitige Akt von Praxis und Lehre schon in einen Vertrag umgedeutet ${ }^{111}$.

Während die äußeren Befugnisse stets Frankreich vorbehalten blieben, wurden für die Verteilung der inneren Hoheitsgewalten unterschiedliche, nur teilweise auch im Bundesstaat bekannte und bei weitem nicht so perfektionierte Prinzipien verwendet. In Syrien und im Libanon besaßen sowohl die Fremdverwaltung als auch die beherrschten Staaten jeweils grundsätzlich alle Hoheitsgewalten ${ }^{112}$. Dabei wurde dieses rechtlich übrigens niemals ausdrücklich fixierte Problem grundsätzlich nicht dahin verstanden, daß die Kompetenzausübung durch die Fremdverwaltung die konkurrierende Zuständigkeit des beherrschten Staates aufhob. Diese vollkommene Herrschaftskonkurrenz führte zu einer völligen rechtlichen Durchdringung aller Sphären und damit zu einer völlig einheitlichen Rechtsordnung. In der Praxis wurde dieses für den Status der Staaten und die Rechtssicherheit sehr gefährliche Prinzip allerdings nur bei der Gesetzgebung konsequent durchgeführt, während die Übernahme der Verwaltungsaufgaben durch die Fremdverwaltung entsprechende Verwaltungszweige der Staaten und die Ausübung der Gerichtsbarkeit durch die Religionsgemeinschaften und Staaten entsprechende Gerichte der Fremdverwaltung ausschloß.

In allen anderen Kolonialgebieten waren dagegen die inneren Kompetenzen zwischen der Fremdverwaltung und dem beherrschten Staat aufgeteilt. In Indochina wurde hierfür das Personalprinzip verwandt, waren also grundsätzlich die Protektoratsstaaten für ihre eigenen, die Fremdverwaltung für alle anderen Staatsangehörigen zuständig; die Fremdverwaltung konnte darüber hinaus aber nach ihrem Belieben ganze Verwaltungszweige und damit auch die Gesetzgebung über die entsprechenden Materien an sich ziehen ${ }^{113}$. Dieses bei der Gesetzgebung, Verwaltung und Gerichtsbarkeit gleichmäßig angewandte Prinzip führte zu einer vollkommenen Trennung der Rechtssphären („dual sovereignty, dual federalism“). In Afrika wurden die Befugnisse dagegen von Anfang an nach Materien abgegrenzt. Auch hier wurde der Dualismus insoweit angestrebt, als Gesetzgebung und Verwaltung nach denselben Kriterien aufgeteilt wurden. $\mathrm{Da}$ die Abgrenzung nach Materien aber immer zu gewissen Überschneidungen führt und die Übereinstimmung der Gesetzgebungs- und Rechtsprechungsmaterien noch nicht einmal angestrebt wurde, finden sich hier mannigfache Durchdringungen der relativ getrennten Rechtssphären. $\mathrm{Zu}$ einer ähnlichen Rechtslage kam es in Indochina nach der ersten Kompetenzübertragung im Jahre 1946114.

Im Bereich der Kompetenzverteilung führte der Dekolonisierungsprozeß in Syrien und im Libanon sowie in Indochina in seiner ersten Phase zu einer Zuständigkeitsfixierung (Besatzungsstatut!), die insbesondere das Recht der Fremdverwaltung beseitigte, ständig weitere Verwaltungszweige und damit die Gesetzgebung über die entsprechenden Materien an sich zu ziehen ${ }^{115}$. In Indochina wurde in dieser Phase überdies die Kompetenzverteilung zumindest partiell vom Personal - auf das Prinzip der Aufteilung nach Materien umgestellt. Im übrigen wurde in diesen Gebieten wie in Afrika bei jeder Phase eine neue Kompetenzschicht („tranche de compétences") vom herrschenden auf die beherrschten Staaten übertragen, denen

111 Togo und Kamerun (S. 298 ff.); französische Gemeinschaft (S. 320, 393).

112 S. $29 \mathrm{ff} ., 32 \mathrm{ff}$.

113 S. 92 ff., $106 \mathrm{ff}$

114 S. $130 \mathrm{f}$.

115 S. $130 \mathrm{f}$. 
relativ früh die Restkompetenz zugebilligt wurde. Darüber hinaus schlossen sich die beherrschten Staaten manchmal sehr bald gegen eine unmittelbare Einwirkung der Fremdverwaltung ab: Die Kompetenzen des Herrscherstaates wurden nur noch dazu benutzt, den beherrschten Staaten entsprechende Verpflichtungen aufzuerlegen $^{116}$. Das gilt insbesondere von der auswärtigen Gewalt: Die Staaten waren der französischen Republik gegenüber verpflichtet, französische Verpflichtungen gegenüber Drittstaaten auf ihrem Territorium auszuführen ${ }^{117}$.

d) Die Einhaltung dieser Kompetenzen und die Übereinstimmung der in ihrem Rahmen ergangenen Akte der Fremdverwaltung und des beherrschten Staates mit dem umgreifenden Recht wurde nur selten nach bundesstaatlichen Prinzipien gewährleistet. Insbesondere kam die politische Überordnung der Fremdverwaltung nicht notwendig auch im höheren rechtlichen Rang ihrer Akte zum Ausdruck. In Indochina konnte die Rangfrage schon wegen des Dualismus der beiden Rechtsordnungen keine Rolle spielen ${ }^{118}$. Selbst in der einheitlichen, das Recht der Fremdverwaltung und der einheimischen Staaten umfassenden Rechtsordnung des Mandatsgebiets Syrien/Libanon wurde aber, soweit ersichtlich, die Rangfrage niemals ausdrücklich gestellt, doch scheinen die Akte der Fremdverwaltung und der Staaten denselben Rang besessen $\mathrm{zu}$ haben ${ }^{119}$. In beiden Fällen wurde die Einheit nicht durch den Rang, sondern durch den politischen Einfluß und die Kontrolle der Fremdverwaltung, in Indochina darüber hinaus noch durch mannigfaltige Delegationen ${ }^{120}$ gesichert. Sobald die äußeren Rechtsnormen aber wie in Afrika eine größere Rolle als die innerdienstlichen Beziehungen spielen, erfüllt der Rang eine wichtige Funktion. Dabei wurde die Kontrolle in Afrika aber zunächst rein verwaltungsrechtlich ${ }^{121}$, später ohne Übergang plötzlich völkerrechtlich konstruiert ${ }^{122}$. Darüber hinaus führte der höhere politische und kulturelle Rang des französischen Rechts zu vom internationalen Privatrecht stark abweichenden Regeln der Normenkonkurrenz ${ }^{123}$.

e) Mit jeder Phase des Unabhängigkeitsprozesses wuchs auch die Beteiligung der beherrschten Staaten oder ihrer Bevölkerung an der Ausübung der französischen Hoheitsgewalt. Diese Mitwirkung fiel grundsätzlich aber auch dann noch in den französischen Rechtsraum und wurde deshalb durch das französische Recht geordnet, wenn sie wie in der französischen Union ${ }^{124}$ und Gemeinschaft ${ }^{125}$ bundesstaatliche Züge annahm. Daneben finden sich aber vereinzelt auch wirklich gemeinsame Institutionen und Befugnisse ${ }^{126}$. Neben der durch die französische Verfassung oder französische Gesetze geregelten Zusammenarbeit finden sich ferner häufig auch auf Vertrag beruhende Gemeinschaften zwischen dem herrschenden und dem beherrschten Staat und auf Vertrag beruhende gegenseitige Verpflichtungen (kooperativer Föderalismus) ${ }^{127}$.

116 Vgl. die Rechtslage in der französischen Gemeinschaft, S. $329 \mathrm{ff}$.

117 S. 150 ff., 182 ff., 221 ff., 228 ff., 292 f., 306 f., 331 f.

118 S. 109.

119 S. $29,33 \mathrm{f}$.

$120 \mathrm{~S} .95 \mathrm{f}$.

121 S. 293 f., 312.

122 S. $361 \mathrm{f}$.

123 S. 100 f., 173 f., 255 f., 257 ff., 278 f., 346 ff., 443 ff.

124 S. $211 \mathrm{ff}$.

125 S. $372 \mathrm{ff}$.

126 Notstandsbefugnisse in Togo und Kamerun (S. $308 \mathrm{f}$.), gemischte Gerichte und Gesetzgebung in Indochina (S. $167 \mathrm{ff}$.), gemischte Behörden in Syrien und im Libanon (S. $58 \mathrm{f}$.)

127 Indochina: S. $150 \mathrm{ff}$., $163 \mathrm{ff}$., Togo und Kamerun: S. 298 ff.; französische Gemeinschaft: S. $334 \mathrm{ff}$. 
f) Der jeweils mehrere beherrschte Staaten erfassende Unabhängigkeitsprozeß führte in Syrien/Libanon, Indochina und Schwarzafrika zu jeweils nach außen abgeschlossenen, nach innen verbundenen Rechtsgebilden, in denen nicht nur der beherrschte Staat zum Herrscherstaat, sondern auch die jeweiligen beherrschten Staaten unter sich in Rechtsbeziehungen standen. Wie im Bundesstaat fiel dabei die Regelung der $z$ wischenstaatlichen Rechtsbeziehungen in die Kompetenz der beherrschten Staaten, die im Rahmen ihrer Aufgaben unter sich Verträge schließen konnten. Wieweit hier die durch die Fremdverwaltung geschaffene umgreifende Einheit schon zerfallen war, zeigt sich dabei in der Tatsache, daß diese Zusammenarbeit über die im Bundesstaat den kooperativen Föderalismus beschränkenden Regeln ${ }^{128}$ weit hinausging. In der Tat hatten die Staaten das Recht, sich untereinander nicht nur $\mathrm{zu}$ technischen, sondern auch zu politischen Gemeinschaften, ja zu Bundesstaaten zusammenzuschließen und diesen Unionen Hoheitsgewalten zu übertragen. So entstanden auch im Dekolonisierungsprozeß zwecks partieller Aufrechterhaltung der zunächst auf die Fremdverwaltung gestützten, umfassenderen Einheit supranationale Gemeinschaften der verschiedensten Art ${ }^{129}$, was erneut eine gewisse Parallelität des Integrations- mit dem Desintegrationsprozeß beweist.

g) Diese kurze Analyse zeigt, daß im Dekolonisierungsprozeß auch bei staatsrechtlichem Grundverhältnis im Organisationsverhältnis die subordinationsrechtlichen allmählich durch koordinationsrechtliche Strukturen verdrängt werden. Dabei stellt sich die Frage nach der rechtlichen Einordnung dieser koordinationsrechtlichen Elemente. Man kann nun versucht sein, dieses Problem mit der Antwort zu lösen, die für die Frage nach dem Völkerrecht im Bundesstaat gilt ${ }^{130}$. In der Tat kann man im Völker- wie im Staatsrecht allgemein die Tendenz feststellen, dem jeweiligen Rechtsgebiet auch an sich typusfremde Strukturelemente solange einzuordnen, bis auch das diese Elemente umgreifende Gebilde eindeutig unter einen Typus der anderen Rechtsordnung subsumiert werden kann: So werden dem an sich subordinationsrechtlich geordneten Staatsrecht auch die im Bundesstaat auftretenden koordinationsrechtlichen Elemente, dem an sich koordinationsrechtlich konstruierten Völkerrecht auch die in den europäischen Gemeinschaften auftretenden subordinationsrechtlichen Elemente zugeschrieben, bis aus dem Bundesstaat eindeutig etwa ein Staatenbund oder aus dem Staatenbund und der Gemeinschaft eindeutig etwa ein Bundesstaat geworden ist. Die außerordentlich starke Flexibilität und damit Anpassungsfähigkeit des Völker- wie des Staatsrechts gestattet, die gesamte Umwandlung als einen plötzlichen Sprung vom Völker- ins Staatsrecht, vom Staats- ins Völkerrecht zu interpretieren, sobald die Quantität in die Qualität umschlägt.

Selbst wenn das Fremdherrschaftsverhältnis insbesondere im Abwicklungsprozeß bundesstaatliche Analogien zeigt ${ }^{131}$, ist diese Betrachtungsweise doch wohl nur statischen Ordnungen, nicht aber dem dynamischen Entwicklungsprozeß ange-

128 Zum kooperativen Föderalismus vgl. das Gutachten über die Finanzreform in der Bundesrepublik Deutschland; G. Konow, Kooperativer Föderalismus und Gemeinschaftsaufgaben, DƠV 1966, S. 368; U. Scheuner, Wandlungen im Föderalismus der Bundesrepublik, DOV 1966, S. 513 und die Entscheidung des Bundesverwaltungsgerichts vom 5. 11. 1965, DOV 1966, S. 415.

129 Syrien und Libanon: S. 59; Indochina: S. $163 \mathrm{ff}$; schwarzafrikanische Staaten: S. $466 \mathrm{ff}$

130 Vgl. hierzu W. Mallmann, Völkerrecht und Bundesstaat, Wörterbuch des Völkerrechts, Bd. 3, 1962, S. $641 \mathrm{ff} ., 648 \mathrm{ff}$; $\mathrm{H}$. Schneider und P. Schaumann, Verträge zwischen Gliedstaaten im Bundesstaat, VeröffVDStRL 1961, Heft 19.

131 Tatsächlich handelt es sich natürlich nicht um Bundesstaaten, vgl. für Syrien und den Libanon S. $42 \mathrm{ff}$ für Indochina S. 106 ff., 133 ff., 211 ff., für Togo und Kamerun S. 297 f., für die französische Gemeinschaft S. $372 \mathrm{ff}$. 
messen ${ }^{132}$. Trotz der Abneigung des Juristen gegen im Fluß befindliche Machtverhältnisse ${ }^{133}$ und der Schwierigkeit, dem sozialen Wandel und Konflikt mit einer systematischen Theorie der normativen Ordnung beizukommen ${ }^{134}$, muß auch die Rechtswissenschaft versuchen, der Evolution gerecht werdende Theorien zu entwickeln. Dabei darf die vertikale Einheit, welche die strukturell einander entsprechenden Elemente der aufeinanderfolgenden Phasen verbindet, nicht zugunsten der horizontalen Einheit zerschnitten werden, in welcher die statische Theorie selbst heterogene, aber im Querschnitt nur einer Phase nebeneinander stehende Elemente $\mathrm{zu}$ verbinden sucht. In der Tat entspricht es der von allen Beteiligten gewollten Kontinuität im Entwicklungsprozeß am besten, wenn die koordinationsrechtlichen Elemente von vornherein dem Völkerrecht zugeordnet werden, die neuen Staaten also im Innenraum eine zunächst beschränkte, allmählich aber wachsende Völkerrechtssubjektivität erwerben, bis diese bei der Gewährung der Unabhängigkeit auch nach außen durchstößt.

\section{Der Unabhängigkeitsprozeß wird durch eine Unabhängigkeitserklärung beendet}

a) Im französischen Rechtsraum finden sich Beispiele für alle drei möglichen Formen der Unabhängigkeitserklärung. In Syrien/Libanon ${ }^{135}$ und in Indochina ${ }^{136}$ stoßen wir auf wegen des französischen Widerstandes allerdings erfolglos gebliebene einseitige Unabhängigkeitserklärungen des beherrschten Staates, in Syrien und im Libanon auf einseitige Unabhängigkeitserklärungen des Herrscherstaats ${ }^{137}$, in Syrien/Libanon ${ }^{138}$, Indochina ${ }^{139}$ und Schwarzafrika ${ }^{140}$ auf zweiseitige Unabhängigkeitsverträge zwischen dem herrschenden und dem beherrschten Staat.

Diese Typusbildung stützt sich zunächst nur auf die äußere Form und den Wortlaut der Erklärungen. Man muß deshalb die Frage stellen, ob dieser formalen eine theoretische Klassifizierung entspricht. Das wird von der strengen Souveränitätstheorie verneint, die alle staatsrelevanten Strukturen auf den Willen des betreffenden Staates zurückführt ${ }^{141}$. Ebenso wie der Staat sich und seine Verfassung nur autonom setzen könne, muß nach dieser Theorie der Gebiets- und Kompetenztransfer als einseitige Dereliktion des Herrscherstaates und nachfolgender Kompetenzausdehnung des beherrschten Staates aufgefaßt werden ${ }^{142}$. Die diesem Modell nicht entsprechenden Akte sind entsprechend umzudeuten; ein der Form nach derivativer ist also theoretisch als originärer Gebiets- und Kompetenzerwerb zu konstruieren („Ausdehnungstheorie“"143).

132 Für das folgende vgl. im einzelnen S. $303 \mathrm{ff}$., $376 \mathrm{f}$.

$133 \mathrm{Vgl}$. W. E. Weyrauch, The Personality of Lawyers, 1964, S. 281.

134 C. W. Mills, Kritik der Soziologischen Denkweise, Soziologische Texte Bd. 8, 1963, S. 84 f.

135 S. $49 \mathrm{f}$.

136 S. $118 \mathrm{ff}$.

137 S. $52 \mathrm{ff}$.

138 S. $48 \mathrm{ff}$.

139 S. $143,147 \mathrm{ff} ., 216 \mathrm{ff}$.

140 S. $384 \mathrm{ff}$

141 G. Jellinek, Allgemeine Staatslehre, 3. Aufl. 7. Neudrudk, 1960, S. 489 ff.: „Selbstbestimmung, Selbstorganisation, Selbstverpflichtung des Staates ${ }^{\alpha}$.

142 Für die Staatensukzession vgl. G. Jellinek a. a. O., S. $278 \mathrm{ff}$; O'Connel, The Law of State Succession 1956, S. $6 \mathrm{ff}$; H. Kelsen, Allgemeine Theorie, S. 320.

143 Soweit eine solche Umdeutung nicht möglich ist, wird der Staatscharakter geleugnet. Insbesondere bei den heteronomen Verfassungen und der heteronomen Unabhängigkeitserklärung erscheint eine soldhe Methode heute nicht mehr möglich, ganz abgesehen davon, daß sie hier eine Erklärung überhaupt schuldig bleibt. 
$\mathrm{Da}$ diese Theorie auf einer bestimmten Staatskonzeption beruht, kann sie durch Fakten nicht widerlegt, aber auch nicht bewiesen werden. Wie bei anderen Theorien kommt es darauf an, ob sie für die Erklärung der juristischen und politischen Vorgänge brauchbar ist ${ }^{144}$. Sicherlich entspricht sie nun dem politischen und juristischen Gehalt der autonomen Staats- und Verfassungsgründungen sowie der einseitigen Kompetenzusurpation, die einzelne oder alle Befugnisse des Herrscherstaates erfassen kann. Politisch und juristisch sind von dieser einseitigen Ausdehnung aber die Staats- und Verfassungsgründung, der Gebiets- und Kompetenztransfer und die Unabhängigkeitserklärung durch Akte des Mutterlandes oder Verträge des herrschenden mit dem beherrschten Staat völlig verschieden. Die Theorie der einseitigen Ausdehnung kann den politischen und historischen Gehalt dieser historischen Vorgänge und insbesondere die angestrebte Kontinuität schon ihrem statisch-logischen Ansatz nach gar nicht gerecht werden. Um diese politischrechtlichen Vorgänge richtig zu deuten, muß also an der anfänglichen Dreiteilung der Unabhängigkeitserklärungen festgehalten werden. Nur ist dabei darauf zu achten, daß die äußere Form und der Wortlaut dieser Akte nicht immer entscheidend ist: über diese Formalien ist vielmehr auf den objektiven Sinn der Vorgänge einzugehen.

Die Souveränitätstheorie kann also nur einen möglichen Typus der genannten historischen Vorgänge politisch-rechtlich erklären. Dabei ist aber zu beachten, daß diese Theorie auch nur in zweiter Linie eine solche Erklärung liefern will. Ihre eigentliche Aufgabe ist statisch-logischer Natur: Ohne Rücksicht auf die historischen Vorgänge soll sie, wenn der Staat und seine Unabhängigkeit erst einmal begründet ist, die Gesamtheit aller staatlichen Elemente zu einem einheitlichen System verbinden. Sie hat damit eine ähnliche Funktion wie die verschiedenen Theorien des Staats- und Gesellschaftsvertrages, die ebenfalls ja nicht den historischen Vorgang der Staatsgründung erklären wollen ${ }^{145}$.

$\mathrm{Da}$ die dynamische und die statische Theorie verschiedene Funktionen haben, müssen sie trotz gewisser Widersprüche nebeneinander, das heißt aber jeweils auf der ihrer Funktion entsprechenden Ebene angewandt werden.

b) Die Unabhängigkeitserklärung im engeren Sinne hebt grundsätzlich alle Beziehungen zwischen dem herrschenden und dem beherrschten Staat auf die Ebene des Völkerrechts ${ }^{146}$. Trotz dieser im Völkerrecht belegenen Wirkung kann, wie die drei möglichen Formen der Unabhängigkeitserklärung zeigen, der auslösende Akt in verschiedenen Rechtsordnungen stehen. So fällt die einseitige Unabhängigkeitserklärung durch den Herrscherstaat seiner Struktur und deshalb auch seinen Voraussetzungen nach noch in seine die Fremdverwaltung und den beherrschten Staat umfassende innere Rechtsordnung, die einseitige Unabhängigkeitserklärung des beherrschten Staates in dessen innere Rechtsordnung, die vertragliche Unabhängigkeitserklärung in den Völkerrechtsraum. Der das Grundverhältnis ändernde Akt kann also noch der alten oder schon der neuen Rechtsordnung zuzurechnen sein. Eine ähnliche Erscheinung finden wir im Integrationsprozeß, wo der neue Staat noch durch einen Vertrag oder schon durch eine Verfassung gegründet werden kann ${ }^{147}$. Bei beiden Richtungen des Entwicklungsprozesses kann der das Grund-

144 Dagegen wendet sich soweit ersichtlich nur H. Kelsen a. a. O., S. 53 ff. Dagegen benutzt etwa H. Huber in seinem Werk über die Verfassungsgeschichte ähnliche Ansätze wie hier.

145 Vgl. hierzu neuerdings W. Hennis - Hans Maier, A. Voigt, Der Herrschaftsvertrag, Politica Bd. 16, 1965. $145 \mathrm{Vgl}$. hierzu neuerdings W. Hennis - Hans Maier, A. Voigt, Der

147 Vgl. hierzu die Auseinandersetzung über die Gründung des Norddeutschen Bundes bei E. R. Huber, Deutsche Verfassungsgeschichte, Bd. 3., S. $673 \mathrm{ff}$. 
verhältnis ändernde Akt also noch in der alten oder schon in der neuen Rechtsordnung verankert sein. Auch im zweiten Fall ändert erst der Unabhängigkeitsakt das Grundverhältnis, geht aber logisch so vor, als ob eine Sekunde vor ihm das Grundverhältnis schon geändert worden wäre: Der Akt hebt sich also „am eigenen Zopf“ aus der alten in die neue Rechtsordnung.

c) Diese Wirkung hat allerdings nur die Unabhängigkeitserklärung im engeren Sinne. In der Tat zeigt die Dekolonisierung des französischen Imperiums, daß die Unabhängigkeitserklärungen durchaus verschiedene Folgen hatten und nicht immer die volle Unabhängigkeit bewirkten. Das ergibt sich schon aus der Häufung der Unabhängigkeitserklärungen für ein bestimmtes Gebiet. So hat Frankreich etwa in Syrien/Libanon und in Indochina in jeweils zwei, in Viêt-Nam sogar in drei aufeinander folgenden Phasen die „Unabhängigkeit" der beherrschten Staaten erklärt, obwohl es wesentliche Hoheitsrechte behielt und — wie die Auslegung dieser Akte ergibt - auch behalten sollte.

Eine nähere Analyse dieser Erklärungen zeigt nun, daß man verschiedene Begriffe der Unabhängigkeit und unterschiedliche Wirkungsgrade der Erklärung auseinander halten muß. Wie der ausdrückliche Vorbehalt bestimmter französischer Befugnisse und die meist gleichzeitige Unterstreichung der Zugehörigkeit zu einer den betreffenden Staat mit Frankreich verbindenden, Hoheitsrechte ausübenden Gemeinschaft zeigen, war in den ersten Phasen des Prozesses niemals die volle Unabhängigkeit im Sinne des Völkerrechts gemeint. Wenn dieser völkerrechtliche Begriff überhaupt eine Rolle spielte, dann nur im Sinne eines Prinzips, das im konkreten Falle gegen andere Prinzipien - wie das der Kontinuität und der Zugehörigkeit zu einer umfassenden Gemeinschaft - abgewogen werden mußte. $\mathrm{Da}$ es im Dekolonisierungsprozeß grundsätzlich nur auf die im Verhältnis zwischen dem herrschenden und beherrschten Staat gesetzten Akte ankommt ${ }^{147 a}$, kann der beherrschte Staat sich auch nicht auf die Unabhängigkeitserklärung berufen, um die Rechtswidrigkeit der noch bestehenden Beschränkungen zu behaupten.

Wenn der in der jeweiligen Erklärung verwandte Begriff der Unabhängigkeit festgelegt ist, können noch immer verschiedene Wirkungsgrade in Frage kommen. Dabei sind zunächst von den deklaratorischen ${ }^{148}$ die verpflichtenden und die gestaltenden Erklärungen zu unterscheiden. Die Rechtsgestaltung kann wiederum in der unmittelbaren und der nur grundsätzlichen Unabhängigkeit bestehen. Bei der unmittelbaren Unabhängigkeit fallen aufgrund des Unabhängigkeitsaktes selbst die mit dem jeweiligen Unabhängigkeitsbegriff nicht vereinbaren Souveränitätsschranken fort und erwirbt der beherrschte Staat die entsprechenden Kompetenzen. Bei der nur grundsätzlichen Unabhängigkeitserklärung erwirbt der beherrschte Staat aufgrund der Erklärung zunächst nur eine Art Anwartschaft auf die Unabhängigkeit, die erst noch durch konkrete weitere Akte, insbesondere durch Kompetenzübertragungen ${ }^{149}$ realisiert werden muß ${ }^{150}$. Die grundsätzliche Unabhängigkeit kann dabei das Herrschafts- in ein Liquidationsverhältnis überführen, in dessen Rahmen der Herrscherstaat bei der Ausübung der zu übertragenden Befugnisse wie in einem Geschäftsführungsverhältnis beschränkt ist ${ }^{151}$.

147a S. $384 \mathrm{ff} ., 405$.

148 Damit sind die Unabhängigkeitserklärungen gemeint, die entweder nur einen unverbindlichen Programmsatz aufstellen oder eine schon vorher eingetretene Rechtsänderung nur anerkennen.

149 Beispiele solcher Transferverträge finden sich auf S. 61, $216 \mathrm{ff}$., $384 \mathrm{ff}$.

150 S. $66 \mathrm{ff}$.

151 S. $72 \mathrm{ff}$. 
Untersucht man nun die einzelnen Unabhängigkeitserklärungen, dann zeigt sich, wie schwer durch einen solchen Akt die volle Unabhängigkeit zu vermitteln ist. In der Tat wurden den Unabhängigkeitsklauseln in aller Regel ohne Rücksicht auf ihren Wortlaut die Unabhängigkeitsbegriffe und Wirkungen beigelegt, welche die Rechtslage am wenigsten beeinflußten; häufig entfielen nur die Souveränitätsbeschränkungen und erwarben die beherrschten Staaten nur die Kompetenzen, welche in den Akten ausdrüclslich hervorgehoben wurden. Hier zeigt sich also deutlich, daß das für einen geordneten Ablauf des Dekolonisierungsprozesses so wesentliche Kontinuitätsprinzip für den beherrschten Staat nicht nur Vorteile bringt. Trotzdem erscheint diese Auslegungstendenz jedenfalls in beschränktem Umfang gerechtfertigt. Auf der einen Seite mußten nämlich die vielfältigen bisherigen durch neue Rechtsbeziehungen abgelöst werden; das wörtliche Verständnis der Unabhängigkeitsklausel hätte aber alle bisherigen Beziehungen ersatzlos aufgehoben (tabula rasa). Zum anderen waren die Staaten meistens auch gar nicht in der Lage, alle Befugnisse von heute auf morgen zu übernehmen. Deshalb kann der Unabhängigkeitsklausel in der Regel nur die Wirkung der grundsätzlichen Unabhängigkeit beigelegt werden, die durch besondere nachfolgende Akte auszufüllen ist. Dabei kann die grundsätzliche Unabhängigkeit insoweit internationale Bedeutung gewinnen, als sie von dritten Staaten anerkannt werden kann und bei der Auslegung internationaler Verträge, welche auf die Unabhängigkeit des betreffenden Staates abstellen, berücksichtigt werden muß ${ }^{152}$.

Soweit auf der anderen Seite die Staaten aufgrund der Erklärung voll unabhängig werden sollten, mußten angesichts dieser Auslegungsprinzipien neue Techniken entwickelt werden. $\mathrm{Zu}$ diesem $\mathrm{Zweck}$ wurde einerseits die Unabhängigkeitsklausel vervollständigt und durch eine allgemeine Transferklausel ergänzt, zum anderen die Unabhängigkeits- von den Assoziations- oder Kooperationsverträgen, welche die neuen Beziehungen regelten, räumlich oder sogar zeitlich getrennt ${ }^{153}$.

d) Bei nur politisch fremden Gebieten ändert die Unabhängigkeitserklärung im engeren Sinn wie dargelegt nicht mehr nur das Organisations-, sondern auch das Grundverhältnis, das hier vom Staats- ins Völkerrecht hinüberspringt. Das bedeutet aber, daß spätestens von diesem Zeitpunkt an der Herrscherstaat seine Beziehungen zum beherrschten Staat nicht mehr einseitig ändern kann. Dieser Zeitpunkt kann aber auch schon vorher oder erst nachher eintreten. Vorher könnte dieser Zeitpunkt eintreten, wenn im Organisationsverhältnis die Beziehungen zum Herrscherstaat schon koordinationsrechtlich geregelt sind und der beherrschte Staat nach innen eine vom Herrscherstaat weitgehend abgeschlossene Herrschaftsordnung verwirklicht oder sogar alle oder einen Teil der äußeren Befugnisse selbständig ausübt. Das im Dekolonisierungsprozeß sich allmählich durchsetzende Selbstbestimmungsprinzip könnte darüber hinaus dem Herrscherstaat insoweit Grenzen ziehen, als der in der jeweiligen Phase verwirklichte Standard in der nächsten Phase nicht mehr beeinträchtigt, sondern nur noch zur Unabhängigkeit als dem Ziel dieses Prozesses hin weiter entwickelt werden darf. Auf der anderen Seite könnte dieser Zeitpunkt insbesondere dann hinausgeschoben sein, wenn der Herrscherstaat unter bestimmten Voraussetzungen (allerdings nicht $\mathrm{zu}$ eng bemessene) Vorbehaltsrechte ausüben darf.

152 Vgl. S. 71.

153 S. 219 f., $404,406 \mathrm{f}$. 
In allen Fällen zeigt sich, daß die sogenannte „actus-contrarius-Doktrin“, nach der jeder Akt von denselben Organen im selben Verfahren geändert oder aufgehoben werden kann ${ }^{154}$, nur im horizontalen Verhältnis jeder Phase, nicht aber im vertikalen Verhältnis mehrerer Phasen zueinander Wirkung beanspruchen kann ${ }^{155}$. Für eine nähere Untersuchung dieser Fragen gibt das im französischen Kolonialreich angefallene Material allerdings nur wenig Anhaltspunkte ${ }^{156}$.

\section{Die dargelegten Eigenheiten der Fremdherrschaft und des Desintegrationspro- zesses verlangen eine neue Auffassung der Staatensukzession}

a) Im Gegensatz zur Auffassung von E. Kordt ${ }^{157}$ ist dabei der entscheidende Unterschied nicht in der Tatsache $\mathrm{zu}$ sehen, daß der herrschende und der beherrschte Staat sich über die Nachfolge sehr weitgehend vertraglich einigen: Diese Erscheinung finden wir ebenso wie die infolge der räumlichen und soziologischen Entfernung der Kolonien vom Mutterland sehr starke Lokalisierung der Verträge, Rechtssätze, Rechte und Verbindlichkeiten schon in den bisher bekannten Fällen der Staatensukzession. Den im 20. Jahrhundert auftretenden Integrations- und Desintegrationsprozessen eigen ist dagegen die Verlagerung des Blickpunkts vom Gebiet auf die Kompetenzen. Wie gezeigt, werden von der Fremdherrschaft häufig nicht alle, sondern nur bestimmte Kompetenzen über ein Gebiet in Anspruch genommen (Kompetenzannexion, Kompetenzzession), so daß man nicht mehr von einer Gebiets-, sondern nur noch von einer Kompetenzhoheit sprechen kann. Im Dekolonisierungsprozeß können dann natürlich auch nur diese Kompetenzen vom herrschenden auf den beherrschten Staat übergehen. Selbst wenn der Herrscherstaat aber im Ausgangspunkt die volle Gebietshoheit besitzt, wird diese in aller Regel nicht en bloc, sondern wird in jeder Phase des Entwicklungsprozesses eine bestimmte Schicht von Befugnissen auf die beherrschten Staaten übertragen. In ganz ähnlicher Weise übernehmen manchmal internationale Gemeinschaften bestimmte Funktionen von anderen Organisationen.

Darüber hinaus ist zu berücksichtigen, daß Vorgänger und Nachfolger sich im Dekolonisierungsprozeß nicht wie bei der Gebietssukzession als jeweils geschlossene Wirkungseinheiten gegenüberstehen, die Kompetenzen also in Abweichung von der die Staaten als geschlossene Rechtssubjekte betrachtenden Völkerrechtsdoktrin nicht immer von der Französischen Republik auf die neuen Staaten, sondern - je nach der Kompetenzverteilung auf der einen und der anderen Seite - von der Französischen Republik oder den dieser ein- und untergeordneten Rechtspersonen Kolonialunion und Kolonie auf die Staaten oder von diesen gebildete supranationale Organisationen übergingen; die Kompetenzverteilung innerhalb der französischen Republik und zwischen den Staaten und deren supranationalen Organisationen spielt also hier eine entscheidende Rolle.

154 Vgl. hierzu A. Bleckmann, Die Mitwirkung des französischen Parlaments bei Abschluß, Aufhebung und Anderung von Verträgen, ZaöRV Bd. 26, 1966, S. $310 \mathrm{ff} ., 346$.

155 Aud bestimmte Konfliktsregeln haben diesen rein statischen Charakter und sind deshalb bei den vertikalen Integrations- und Desintegrationsprozessen nicht mehr anwendbar (vgl. hierzu H. P. Ipsen, Das Verhältnis des Rechts der europäischen Gemeinschaften zum nationalen Recht, in: Aktuelle Fragen des europäischen Gemeinschaftsrechts, 1965, S. $1 \mathrm{ff}$., $24 \mathrm{f}$.

156 Vgl. aber zum Verhältnis von Vertrag und einseitigem Akt S. 299 ff.

157 a. a. O. 
Dem allmählichen Übergang von Kompetenzschichten ist schließlich eigen, daß sich die Nachfolgefrage bei jeder Phase neu stellt. Dem langsamen Hinübergleiten aller Rechtsbeziehungen ins Völkerrecht entspricht es dabei, daß der Rechtscharakter der jeweils meist gleichen Regeln nicht immer völlig klar ist.

b) Bei Integrations- und Desintegrationsprozessen sollte man deshalb von Kompetenz- oder Funktionsnachfolge sprechen ${ }^{158}$. Tatsächlich wird dieser Terminus auch bei der Nachfolge in internationale Organisationen ${ }^{159}$ und bei infolge innerstaatlicher Kompetenzverschiebungen auftretenden Nachfolgefragen ${ }^{160}$ schon verwandt. $\mathrm{Ob}$ auch die Gebietsnachfolge als Nachfolge in Kompetenzen aufgefaßt werden soll161, ist damit noch nicht entschieden. Ebenfalls läßt dieser Terminus die Streitfrage offen, ob die Sukzession als eine automatische Nachfolge oder nur als Pflicht des Nachfolgers konstruiert werden soll, in die Rechtsstellung des Vorgängers einzutreten ${ }^{162}$. Ebenso wie die "Ausdehnungstheorie“ hängt diese letzte Frage davon $a b$, ob man dem Souveränitätsdogma ${ }^{163}$ oder dem die faktischen Vorgänge besser erklärenden Kontinuitätsprinzip folgen will. Ohne die im Verhältnis zwischen Frankreich und den neuen Staaten angewendeten Regeln hier im einzelnen darstellen zu wollen, kann man aber hervorheben, daß bei jeder neuen Kompetenzschicht der beherrschte Staat mehr oder weniger automatisch in die aufgrund dieser Kompetenzen ergangenen Rechtssätze, die hiermit verknüpften Rechte und Pflichten und das diesen Funktionen gewidmete Vermögen eintrat.

c) Obwohl bei der in den beherrschten Staat integrierten Fremdverwaltung die von dieser gesetzten Akte formalrechtlich dem mit sich selbst auch nach der Unabhängigkeit grundsätzlich identisch bleibenden beherrschten Staat zugerechnet werden, führt hier der Wechsel der politischen Souveränität von der Fremdverwaltung auf den beherrschten Staat zu einem so starken Bruch in der soziologischen Kontinuität, daß auch die Weitergeltung dieser Akte den Regeln der Funktionsnachfolge unterstellt werden kann. Dasselbe gilt trotz der formalrechtlichen Identität für die aus den Kolonien sich zu „territoires d'outre-mer“ und Gemeinschaftsstaaten entwickelnden neuen unabhängigen Staaten Afrikas, wo ebenfalls in einem bestimmten Punkt die politische Herrschaft von der französischen Verwaltung auf die Bevölkerung und ihre Repräsentanten überging.

d) Beim Dekolonisierungsprozeß wechseln die Beziehungen zwischen dem herrschenden und dem beherrschten Staat und zwischen den beherrschten Staaten allmählich vom Staats- ins Völkerrecht über. Die für diese Beziehungen ursprünglich einseitig gesetzten Akte des Herrscherstaates können dabei im Gegensatz zu den

$158 \mathrm{Daß}$ es eine solche Nachfolge gibt, folgt aus den rechtlichen Fakten. Dann ist es aber eine rein terminologische Frage, ob man mit der herrschenden Lehre (vgl. etwa E. Menzel, Staatensukzession, Wörterbuch des Völkerrechts, Bd. 3, 1962, S. 306; P. Guggenheim, Beiträge zur völkerrechtlichen Lehre vom Staatenwechsel, 1925, S. $44 \mathrm{ff}$.; D. P. O'Connel, The Law of State Succession, 1956, S. $1 \mathrm{ff}$.) nur die Gebietsnachfolge und nicht auch die Kompetenznachfolge als "Staatensukzession“ begreift. Eigenartigerweise begreift O’Connel a. a. O. S. $31 \mathrm{ff}$. dann doch die "partial succession“ in die Staatensukzession ein.

$159 \mathrm{H}$. Chiu, Succession in International Organisations, Int. Comp. L. Q. 1965, S. 83; H. J. Hahn (Die Organisation für Wirtschaftliche Zusammenarbeit und Entwicklung, ZaöRV Bd. 22, 1962, S. 49 ff., 57) spricht von der ${ }_{n}$ funktionellen Kontinuität ${ }^{\alpha}$.

$160 \mathrm{Vgl}$. neuerdings $\mathrm{K}$.-O. Hütter, Bindung der Länder an die Schulbestimmungen des Reichskonkordats von 1933. Rechtsnachfolge oder Funktionsnachfolge, Diss. 1964.

$161 \mathrm{Vgl}$. J. D. Gonzâlez Campos, Algunas consideraciones sobre los problemas de la succesión de Estados, Rev. Esp. Der. Int. 1963, S. $551 \mathrm{ff}$., $567 \mathrm{ff}$.

162 Vgl. hierzu neuerdings J. A. Shearer, La succession d'Etats et les traités non localisés, RGDIP 1964, S. 5; P. Guggenheim a.a.O., S. $42 \mathrm{ff} . ;$ L. Caflisch, The Law of State Succession. Theoretical observations, 163 s. 0 . Netherlands Int. Law Review 1963, S. 337. 
Verträgen wegen des Fortfalls der umfassenden staatsrechtlichen Einheit nur noch als Recht der einzelnen Staaten, nicht mehr als diesen übergeordnetes Recht weitergelten, weil dem Völkerrecht solche einseitigen Akte grundsätzlich fremd sind. Nur vereinzelt finden sich Völkerrechtssätze, die wie etwa die uti-possidetisDoktrin ${ }^{164}$ solche einseitigen Akte tragen. Um diese Bindung aufrechtzuerhalten, wurden diese Akte deshalb manchmal in Verträgen verankert. Auf der anderen Seite schlossen sich die beherrschten Staaten häufig zu supranationalen Gemeinschaften zusammen, die solche einseitigen Akte tragen können und auf die deshalb im Rahmen ihrer Kompetenzen das entsprechende Recht überging.

e) Die zwischen Frankreich und den neuen Staaten vereinbarten Nachfolgeprinzipien weichen manchmal ganz erheblich von den allgemeinen Regeln der Staatensukzession ab. Darüber hinaus wurde im Unabhängigkeitsprozeß auch nicht auf von Gebiet zu Gebiet und von Phase zu Phase einheitliche Prinzipien zurückgegriffen. Diese doppelte Abweichung erklärt sich mindestens teilweise aus zwei Umständen: Einmal sollte eine größere Kontinuität als bei der normalen Sukzession erzielt werden, zum anderen verlangte der Unabhängigkeitsprozeß eine ständige französische Hilfe bei der Entstehung und Entwicklung der neuen Staaten: Der Gedanke der unter die Entwicklungshilfe fallenden „Erstausstattung“ mit sachlichen, personellen und rechtlichen Mitteln spielte also eine erhebliche Rolle.

Das gilt wahrscheinlich auch für den Dekolonisierungsprozeß im britischen, niederländischen und spanischen Bereich. Vereinzelt besteht umgekehrt die Tendenz, die neuen Staaten von Verpflichtungen des Mutterlandes weitgehend freizustellen. Selbst wenn sich trotzdem gewisse einheitliche Regeln finden lassen sollten, dürften die vorangehenden Erwägungen es ausschließen, das im Dekolonisierungsprozeß entwickelte Recht der Staatensukzession unbesehen auf alle Sukzessionsformen zu erweitern. Es fragt sich deshalb, ob für eine allgemeine Kodifikation des Sukzessionsrechts, wie sie die International Law Commission plant, heute der richtige Zeitpunkt ist. 